\title{
DOS AÑOS DE JURISPRUDENCIA CONSTITUCIONAL ESPAÑOLA *
}

POR

\author{
PEDRO CRUZ VILLALON
}

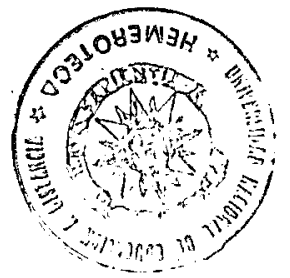

\section{SUMARIO}

1. La posición y los cometidos del Tribunal Constitucional: 1.1. La presentación del Tribunal Constitucional. 1.2. Los procesos constitucionales: 1.2.1. El control de constitucionalidad: los procesos de constitucionalidad. 1.2.2. El recurso de amparo constitucional. 1.2.3. Los conflictos de competencias. 1.2.4. Otros procesos constitucionales. 1.3. Algunos aspectos de la actuación del Tribunal: 1.3.1. Los votos particulares. 1.3.2. El estilo de las sentencias. 1.3.3. La potestad reglamentaria del Tribunal.-2. LA INTERPRETACIÓN DE LA CONSTITUCióN: 2.1. El ordenamiento jurídico: 2.1.1. La Constitución como norma jurídica. 2.1.2. Los Estatutos de Autonomía. 2.1.3. Las leyes orgánica. 2.1.4. La Ley. 2.1.5. Otras categorías normativas. 2.2. Los derechos fundamentales: 2.2.1. La naturaleza de los derechos fundamentales. 2.2.2. $\mathrm{El}$ «contenido esencial» de los derechos fundamentales. 2.2.3. Los límites de los derechos: Los servicios esenciales. 2.2.4. Retroactividad de la Constitución en materia de derechos fundamentales. 2.2.5. Efectos frente a terceros. 2.2.6. El principio de garantía material de los derechos. 2.2.7. Los «principios rectores de la política social y económica». 2.2.8. La jurisprudencia del Tribunal Europeo de Derechos Humanos. 2.3. El Estado y las Comunidades Autónomas: 2.3.1. La forma de Estado. 2.3.2. El principio de autonomía y la doctrina de los intereses territoriales. 2.3.3. La distribución de competencias: La noción material de bases.-3. CoNCLusrón.

Con la restauración del Estado de Derecho España intenta consolidar por segunda vez en su historia ${ }^{1}$ un sistema de justicia constitucional concentrada, como instrumento jurídico de garantía de la primacía de la Constitución. La puesta en marcha de este sistema se ha producido de forma

* Informe realizado para la «Zeitschrift für ausländisches öffentliches Recht und Völkerrecht», 43/1 (1983), págs. 70-117.

${ }^{1} \mathrm{La}$ Constitución de la II República, de 9 de diciembre de 1931, instituía un «Tribunal de Garantías Constitucionales», que funcionó con normalidad de 1934 a 1936. Cfr. la jurisprudencia de este Tribunal, con una extensa introducción, en M. Bassols Coma, La jurisprudencia del Tribunol de Garantías Constitucionales de la II República española, Madrid, 1981. Sobre el tema, en lengua alemana, W. Boucsein, Verfassungs. sicherung und Verfassungsgericbtsbarkeit in der zweiten spaniscben Republik (1931-1936), Francfort del M., 1977. 
relativamente rápida: Tras la promulgación de la Constitución el 29 de diciembre de 1978 - con un título específico dedicado al Tribunal Constitucional-, la Ley Orgánica reguladora del mismo es promulgada el 3 de octubre de 1979 , quedando constituido el Tribunal el 12 de julio de $1980^{2}$. El 26 de enero, el Tribunal Constitucional dicta su primera sentencia, alcanzando éstas un total de ciento una sentencias en sus dos primeros años de funcionamiento ${ }^{3}$.

Las páginas que siguen se proponen precisamente ofrecer un balance de la jurisprudencia contenida en este primer período de funcionamiento del Tribunal Constitucional. En un sistema de justicia constitucional concentrada, el primer grupo de sentencias tiene siempre un carácter fundacional y, en este sentido, de algún modo, histórico. Es desde esta perspectiva desde la que fundamentalmente nos proponemos acercarnos a dicha jurisprudencia.

Ocurre, sin embargo, que esta jurisprudencia, por así decir «fundacional», debe enfrentarse necesariamente con cada uno de los grandes problemas de la jurisdicción constitucional; de ahí que resulte imposible ocuparse de cada uno de ellos con el mínimo detenimiento que en otro caso setía inexcusable. A este respecto, el presente trabajo sólo puede pretender reflejar el modo como cada uno de estos grandes problemas se le han planteado al TC y cuál ha sido su primera respuesta.

En este sentido hemos procurado articular el informe que sigue, dentro de lo que ello es posible, en torno a dos apartados: De un lado, todo aquello que esta jurisprudencia contiene acerca de la propia naturaleza y las distintas funciones del TC. De otra parte, ofrecer una visión sucinta, pero lo más expresiva posible acerca de lo que el TC ha avanzado durante este periodo en el camino de la interpretación de la Constitución española, pues también sus primeras afirmaciones en este ámbito suelen tener, y así ha sido, un cierto carácter fundacional.

\section{LA POSICION Y LOS COMETIDOS DEL TRIBUNAL CONSTITUCIONAL}

El TC, en efecto, ha debido esforzarse desde sus primeras sentencias en precisar su posición en el conjunto de los órganos constitucionales del Estado, así como en delimitar el sentido de cada una de sus competencias o, al menos, de todas aquellas que hasta el presente ha tenido ocasión de ejercer.

2 Sobre la Constitución española, en lengua alemana, cfr. H. Schambeck, «Die Verfassung Spaniens 1978», en Ius Humanitatis. Festscbrift für Alfred Verdross, Berlín, 1981, págs. 187.213; A. Weber, «Die spanische Verfassung von 1978», en Jabrbuch des öffentlicben Recbts, N. F., 29 (1980), págs. 209-252, con el texto de la Constitución en apéndice. La bibliografía española sobre la Constitución de 1978 es ya importante. Cfr. «Materiales para el estudio y aplicación de la Constitución española de 1978», en Documentación Jurídica, 25-28 (1980). Por lo que se refiere al Tribunal Constitucional español, cfr., en lengua alemana, H. J. Faller, «Das spanische Verfassungsgericht», en Jabrbuch des öff. Recbts, N.F., 29 (1980), págs. 279-291; U. Vellnagel, Die verfassungssicberung in Spanien seit 1978 unter besonderen Berïcksicbtigung der Verfassungsgerichtsbarkeit. Diss. 1982.

${ }^{3}$ El mes de julio de 1982 completo inclusive. 


\subsection{La presentación del Tribunal Constitucional}

El art. $10^{\circ}$ de la Ley Orgánica del Tribunal Constitucional, con una fórmula bastante próxima a la de la Ley del Tribunal Constitucional Federal alemán, a la vez que precisa su posición de independencia respecto de los restantes órganos constitucionales caracteriza al TC como «intérprete supremo de la Constitución» ${ }^{4}$. El TC se ha apropiado desde su primera sentencia de esta fórmula como la más adecuada para definir su posición en el ordenamiento constitucional español. Para el TC ello significa que la interpretación realizada por él de los preceptos constitucionales «se impone a todos los poderes públicos». Significa también que su función se concreta en la afirmación del «principio de constitucionalidad», principio que no sería sino, precisamente, el de la «vinculación a la Constitución de todos los poderes públicos».

Ahora bien, si el TC no duda en calificarse a sí mismo como auténtico «defensor de la Constitución» ${ }^{5}$, esta afirmación viene inmediatamente completada por la definición de su especial posición respecto del legislador: en un Estado democrático, el legislador expresa la voluntad popular, pudiendo únicamente él modificarla o derogarla; bien es cierto que el TC ha recibido la potestad de declarar la nulidad de un precepto legal cuando infrinja la Constitución, pero «esta potestad sólo puede ser utilizada, sin embargo, cuando así lo exijan razones muy graves y sólidas»; es preciso, previamente, que un órgano constitucional, o parte sustancial de él, afirme previamente la existencia de dicha infracción, o que un órgano judicial considere puede verse obligado a aplicar una norma inconstitucional: «Cuando estas razones graves y sólidas no existen, el respeto al legislador exige que este Tribunal se abstenga de hacer pronunciamiento algunos ${ }^{6}$.

Podría decirse que el TC considera primordial el no ser confundido con el legislador, el asegurar su propio respeto al ámbito del legislador; en una palabra: la «libertad conformadora del legislador»: «Queremos decir que las opciones políticas y de gobierno no están previamente programadas de una

4 «El Tribunal Constitucional, como intérprete supremo de la Constitución, es independiente de los demás órganos constitucionales y está sometido sólo a la Constitución y a la presente Ley Orgánica» (art. 1.1 LOTC). La caracterización del TC como «órgano constitucional» tiene en este precepto un carácter más declarativo que constitutivo, sin la relevancia de la correspondiente afirmación en el art. $10^{\circ}$ de la Ley alemana. De ahí que no se haya producido en España algo similar al Status-Bericbt respecto del Tribunal Constitucional Federal alemán (cfr. Jabrbuch des öff. Recbts, N.F., 6 [1957]), si bien hay ciertos ecos del mismo en el artículo del presidente del Tribunal Constitucional, profesor M. García-Pelayo, «El status del Tribunal Constitucional», en Revista Española de Derecho Constitucional, 1 (1981), págs. 11-34. El sólo hecho formal de la regulación del TC en un título autónomo de la Constitución (el IX) supone una importante clarificación de su status, lo cual ha sido apreciado por el mismo TC al precisar su posición respecto del Poder Judicial: «... el TC, que no forma parte del Poder Judicial y está al margen de la organización de los Tribunales de Justicia, como la propia Constitución pone de manifiesto al regular en títulos diferentes unos y otros órganos constitucionales (el VI y el IX, respectivamente)...» (STC 9/1981, de 31 de marzo, Fto. Jco. 1).

${ }^{5} \mathrm{La}$ expresión aparece esporádicamente; así, por ejemplo, STC $17 / 1981$, de 1 de junio, Fto. Jco. 1.

- STC 17/1981, de 1 de junio, Fto. Jco. 4. 
vez por todas, de tal manera que lo único que cabe hacer en adelante es desarrollar ese programa previo.» La Constitución, por el contrario, «es un marco de coincidencias lo suficientemente amplio como para que dentro de él quepan opciones políticas de muy diferente signo» ${ }^{7}$. El TC no puede constituirse en modo alguno en una amenaza a esa pluralidad política en nombre de la Constitución, porque la Constitución es, ante todo, pluralismo político. Lo que al TC corresponde es «fijar los límites dentro de los cuales pueden plantearse legítimamente las distintas opciones políticas, pues, en términos generales, resulta claro que la existencia de una sola opción es la negación del pluralismo ${ }^{8}$.

Será, en definitiva, esta actitud de principio del TC la que explique su recomendación, expresada desde las primeras sentencias, de agotar siempre las posibilidades de la técnica de la «interpretación conforme» o interpretación de la norma en conformidad con la Constitución antes de declarar su nulidad, recomendación dirigida tanto a los poderes públicos y muy especial al Poder Judicial como practicada por él mismo ${ }^{9}$. Así, la declaración de nulidad de la norma sólo se impondrá cuando la misma atente al «contenido esencial» del derecho fundamental o al «núcleo esencial» de la institución constitucional garantizada. Ello explicará igualmente su actitud, aunque sólo sea de principio, frente a una utilización amplia de la técnica de las «sentencias interpretativas»: «El TC es intérprete supremo de la Constitución, no legislador, y sólo cabe solicitar de él el pronunciamiento sobre adecuación $v$ inadecuación de los preceptos a la Constitución» ${ }^{10}$.

\subsection{Los procesos constitucionales}

Pero, con seguridad, la mejor manera de investigar el modo como el TC entiende su propia función sea relacionándola con cada una de sus competencias, con cada uno de los distintos procesos constitucionales previstos en la Constitución y en la LOTC. Conviene, pues, analizar por separado, primero, las tres competencias fundamentales atribuidas por la Constitución al TC: el control de constitucionalidad (abstracto y concreto), el amparo constitucional y los conflictos de competencia. En segundo término nos ocuparemos de otras competencias de segundo rango, que prácticamente no ha tenido el TC ocasión de ejercer.

\subsubsection{El control de constitucionalidad: los procesos de constitucionalidad}

El TC recibe ante todo de la Constitución la que cabe considerar como la función esencial de un órgano de jurisdicción constitucional concentrada:

7 STC 11/1981, de 8 de abril, Fto. Jco. 7.

8 STC 4/1981, de 2 de febrero, Fto. Jco. 3.

- La declaración de inconstitucionalidad, así, sólo procederá cuando la norma no pueda interpretarse de acuerdo con la Constitución «por ser de un contenido incompatible con la misma. Esta interpretación, de conformidad con la Constitución..., responde además a un criterio de prudencia que aconseja evitar que se produzcan lagunas en el ordenamientos (STC de 2 de febrero de 1981, Fto. Jco. 5).

${ }_{10}$ STC 5/1981, de 13 de febrero, Fto. Jco, 6. 
la capacidad para apreciar la inconstitucionalidad de una norma legal, declarando su nulidad con efectos vinculantes erga omnes, competencia en la que detenta, justamente, una posición de monopolio (art. 161.1.a CE). En este sentido, el art. 27.1 LOTC ha venido a afirmar: «Mediante los procedimientos de declaración de inconstitucionalidad regulados en este título, el TC garantiza la primacía de la Constitución y enjuicia la conformidad o disconformidad con ella de las leyes, disposiciones o actos impugnados» ${ }^{11}$.

Esta función de control de constitucionalidad la realiza el TC a través de las dos vías del control abstracto (recurso de inconstitucionalidad) y del control concreto (cuestión de inconstitucionalidad), pero antes de referirnos a cada una de ellas convendrá ocuparse de las distintas formas a través de las cuales una norma, según el TC, puede incurrir en inconstitucionalidad.

\subsubsection{Las formas de la inconstitucionalidad.}

Procederemos a agrupar en este apartado una serie de problemas de los que el TC ha tenido ocasión de ocuparse ya, y que tienen en común su traducción en distintos tipos y formas de inconstitucionalidad: la que afecta al derecho preconstitucional, la implícita en las llamadas «sentencias interpretativas», la derivada de la que podríamos llamar constitucionalidad «interina».

\subsection{La cuestión del derecho preconstitucional:} la inconstitucionalidad «sobrevenida».

Si la definición de la competencia del TC respecto del derecho preconstitucional supone una cuestión de primer orden en los momentos fundacionales de cualquier jurisdicción constitucional, tanto más habría de serlo en el caso español, dadas las peculiaridades de su proceso de restauración del Estado de Derecho, en ausencia de una ruptura de la legalidad. La cuestión no se hallaba resuelta ni en la Constitución ni en la LOTC, por lo que ha sido el propio Tribunal quien ha debido resolverla a través de su propia jurisprudencia.

$\mathrm{La}$ única cosa que desde el principio estuvo clara es la facultad $-\mathrm{y}$ el deber- de los jueces y Tribunales de considerar derogado, y, por tanto, no susceptible de aplicación, el derecho preconstitucional que aquéllos estimasen se hallaba en contradicción con la Constitución. En ausencia de una prohibición constitucional expresa y en virtud del sólo principio de lex posterior, la Constitución derogaba todo el derecho anterior a la misma que se hallase en contradicción con ella, debiendo los jueces actuar en consecuencia ${ }^{12}$.

${ }^{11}$ STC 14/1981, de 29 de abril, Fto. Jco. 4: «La función principal de los procesos de inconstitucionalidad, cual es la defensa objetiva de la Constitución, el afirmar su primacía y privar de todo efecto a las leyes contrarias a la misma, excluyendo del ordenamiento a las disconformes con la Constitución...»

${ }_{12}$ En puridad, ni siquiera es necesario el apartado $30^{\circ}$ de la Disposición Transitoria CE, en virtud de la cual «quedan derogadas cuantas disposiciones se opongan a lo establecido en esta Constitución». Para el magistrado Rubio Llorente, «tal precepto, aunque tal vez, en rigor, superfluo desde el punto de vista teórico, es ahora utilizado por primera vez en nuestra historia constitucional y no puede tener otro sentido (puesto que ya el apartado $10^{\circ}$ de la misma disposición se refiere a normas supralegales) que el de subrayar la eficacia derogatoria 
Ahora bien, ¿suponía esto que el TC carecía de competencia alguna respecto al derecho preconstitucional, que carecía de cualquier facultad de control sobre el mismo qua tribunal constitucional, es decir, con efectos vinculantes erga omnes, que no cabía plantear ante el TC un juicio de constitucionalidad sobre este derecho, ya sea en forma de control abstracto o de control concreto?

El TC se ha visto obligado a enfrentarse con esta cuestión en su primer proceso de constitucionalidad. En efecto, la Disposición Transitoria 2. ${ }^{\mathrm{a}}$ de la LOTC había dispuesto la reapertura de un plazo de tres meses a partir de la constitucional del TC ${ }^{13}$ para la impugnación directa del derecho promulgado con anterioridad a ese momento (12-7-1980); no se precisaba, sin embargo, que tal derecho hubiera de ser posterior a la Constitución (29-12-1978). Los parlamentarios legitimados para solicitar un control abstracto entendieron que la competencia del TC no se restringía al derecho posconstitucional, solicitando, en virtud de esta disposición transitoria, el control de una Ley del régimen de Franco ${ }^{14}$, otra de los meses de la transición política ${ }^{15}$ anteriores a las primeras elecciones democráticas $y$, por fin, una Ley posconstitucional ${ }^{16}$. Será en las sentencias correspondientes a los dos primeros recursos en los que el TC sentará su doctrina respecto a su propia competencia sobre el derecho preconstitucional.

La sentencia 4/1981, de 2 de febrero, vendrá a afirmar que, en el caso de las leyes preconstitucionales contrarias a la Constitución, se acumulan la derogación (en virtud del principio de lex posterior) y la inconstitucionalidad (en virtud del principio de lex superior); que, en tanto que ley derogada, esta derogación puede y debe ser apreciada por los jueces y tribunales de justicia; pero que, en tanto que ley inconstitucional, el TC es competente para declarar dicha inconstitucionalidad (inconstitucionalidad «sobrevenida») con efectos erga omnes. Con respecto al derecho preconstitucional, el TC comparte su competencia de rechazo con el poder judicial; con respecto al derecho posconstitucional, el TC ostenta el «monopolio de rechazo».

La forma específica de inconstitucionalidad en que incurre el derecho preconstitucional es, según el TC, la llamada «inconstitucionalidad sobrevenida», en expresión tomada del control de constitucionalidad italiano, la cual se caracterizará ante todo porque la declaración de la misma tiene efectos frente a todos, en cuanto procedente del TC ${ }^{17}$. La fórmula utilizada en el fallo será esta vez: «Declarar inconstitucionales y nulos, y derogados por la Constitución...» Esta jurisprudencia la sentaría el TC con el solo voto particular del magistrado Rubio Llorente, que representó, y sigue representan-

que la Constitución tiene respecto de las leyes ordinarias o las normas de rango inferior» (STC 4/1981, de 2 de febrero, voto particular).

${ }_{13}$ Véase infra, 1.2.1.2.1.

${ }^{14}$ En realidad, diversos preceptos relativos al régimen local, contenidos en diversas leyes, aunque muy especialmente en las Leyes de Bases de 1945 y 1953.

${ }_{13}$ El Real Decreto-ley 17/1977, de 4 de marzo, regulador del derecho de huelga.

16 Ley Orgánica $5 / 1980$, por la que se regula el Estatuto de Centros Escolares.

17 STC 4/1981, de 2 de febrero, Fto. Jco. 1. Sobre la forma de inconstitucionalidad «sobrevenida» en la justicia constitucional italiana, cfr. G. Zagrebelsky, La giustizia costituzionale, Bolonia, 1977, págs. 42-48. 
do ${ }^{18}$ en el Tribunal la posición inversa: la de que sólo cabe hablar de «constitucionalidad» o «inconstitucionalidad» de una norma cuando se trate de derecho posconstitucional; que, por lo que hace al derecho preconstitucional, lo único que cabe predicar respecto del mismo es su «derogación»o su «vigencia»; que así como el TC ostenta el «monopolio de rechazo» respecto del derecho posconstitucional, el Poder Judicial ostenta un monopolio paralelo respecto de la derogación o vigencia del derecho preconstitucional. En particular, considera rechazable el concepto «híbrido y contradictorio» de «inconstitucionalidad sobrevenida» ${ }^{19}$.

EI TC se reafirmaría en esta doctrina en la importante sentencia 11/ 1981 , de 8 de abril, recaída en el otro de los recursos de inconstitucionalidad planteados directamente en virtud de la Disposición Transitoria 2.a de la LOTC. Ahora bien, unos días antes, el TC tendría ocasión de precisar el concepto de «inconstitucionalidad sobrevenida» en otro extremo. En efecto, las sentencias 9/1981, de 31 de marzo, y 10/1981, de 6 de abril, en sendos recursos de amparo fijarían la doctrina, desde entonces mantenida por el Tribunal ${ }^{20}$, de que los efectos de la declaración de «inconstitucionalidad sobrevenida» son «mucho más intensos» (no ya sólo, pues, «extensos») que los de la derogación, lo cual se traducía concretamente en la materia de los derechos y libertades fundamentales en que la Constitución actúa con efecto retroactivo afectando a actos producidos con anterioridad, pero cuyos efectos continúan haciéndose sentir tras la entrada en vigor de la Constitución ${ }^{21}$. Ello no significaba, evidentemente, que los efectos de la declaración de inconstitucionalidad sobrevenida pudiesen llegar a ser los mismos a los de la inconstitucionalidad «originaria» (nulidad), pero sí pretendía situarse a medio camino, un medio camino indeterminado, entre nulidad y derogación.

Pasando ya a la mencionada sentencia $11 / 1981$, de 8 de abril, recaída sobre el Real Decreto-ley regulador del derecho de huelga, la misma desarrollaría conceptualmente la doctrina del Tribunal relativa a la extensión de la competencia del TC al ámbito del derecho preconstitucional: derogación e inconstitucionalidad no son dos conceptos que se excluyan mutuamente; por el contratio, la decisión acerca de si una norma se halla vigente o derogada por la Constitución exige un previo juicio de constitucionalidad de aquélla.

18 STC 34/1981, de 10 de noviembre, voto particular.

19 STC 4/1981, de 2 de febrero, voto particular. Un comentario de esta sentencia, ampliamente favorable al voto particular del magistrado Rubio Llorente, M. Aragón, «La sentencia del Tribunal Constitucional sobre leyes relativas al régimen local, anteriores a a Constitución», en Revista Española de Derecbo Constitucional, 1 (1981), págs. 185-205. Decididamente a favor del control del TC sobre el derecho preconstitucional, D. López Garrido, «Un año del Tribunal Constitucional. La fijación jurisprudencial de su función y competencias. El concepto de inconstitucionalidad sobrevenida», en Revista de Derecbo Político, 13 (1982), págs. 199-209.

${ }^{20}$ Véase infra, 2.2.4.

${ }^{21}$ STC 9/1981, de 31 de marzo, Fto. Jco. 3: «Inconstitucionalidad sobrevenida, que afecta a la validez de la norma y que produce efectos de significación retroactiva mucho más intensos que los derivados de la mera derogación.» STC 10/1981, de 6 de abril, Fto. Jco. 7: «Ahora bien, toda ley preconstitucional que se oponga a la Constitución debe entenderse no solamente derogada, sino también inconstitucional, y, en consecuencia, tal invalidez sobrevenida puede producir efectos en situaciones que, aun surgidas con anterioridad a la norma fundamental, produzcan efectos con posterioridad a su entrada en vigor.» 
Esto es algo que el TC considera de una claridad «meridiana», a pesar de no carecer su argumento de cierta petición de principio. La sentencia, por lo demás, explica cómo esta competencia del TC también puede tener lugar a través de un control abstracto y no solamente por la vía del control concreto ${ }^{22}$.

La sentencia 11/1981, de 8 de abril, contenía una cautela, realizada en otro contexto, en base a la cual la competencia del TC se extendía a todos los preceptos - anteriores o posteriores a la Constitución - con tal de que «no se encuentren expresamente derogados» ${ }^{23}$. Pues bien, el TC va a tener ocasión de volverse atrás de esta jutisprudencia unos días más tarde, con ocasión de su primer juicio de control concreto, al considerarse competente para enjuiciar un precepto expresamente derogado con posterioridad a la Constitución, por la sencilla razón de que la decisión acerca de si el precepto quedó tácitamente derogado por la Constitución o expresamente derogado en un momento posterior condicionaba el fallo del tribunal a quo, lo que, a su juicio, lo hacía competente para decidir la cuestión ${ }^{24}$.

Frente a esta sentencia, el magistrado Rubio Llorente cuenta ahora con la solidaridad del magistrado Díez-Picazo, ponente de la sentencia 11/1981, de 8 de abril, en un voto particular en el que tratan de explicar cómo el sentido de la cuestión de inconstitucionalidad es el mismo que el del recurso de inconstitucionalidad, el asegurar la primacía de la Constitución, no el de colaborar en la administración de justicia con los jueces y tribunales: «Siendo esto así, parece bastante claro que no tiene sentido formular un enjuiciamiento sobre normas ya derogadas» ${ }^{25}$.

Al menos, la sentencia procura restringir el planteamiento de cuestiones de constitucionalidad relativas al derecho preconstitucional a los casos en los que «la persistencia de interpretaciones contrarias a la Constitución o la dispersión de criterios reclamen una solución de alcance general», es decir, con eficacia erga omnes. Según el Tribunal, ése era precisamente el caso del precepto sometido a su control ${ }^{26}$.

A lo largo de 1981 el TC tuvo ocasión de reafirmar esta jurisprudencia, haciendo uso del artículo 55.2 LOTC $^{27}$, a fin de que el Pleno del TC declarase la «inconstitucionalidad sobrevenida», es decir, con efectos erga omnes, de un precepto considerado derogado e inconstitucional por la Sala Primera del TC con ocasión de un recurso de amparo ${ }^{23}$. De forma similar, el Pleno se ha reservado el conocimiento de un recurso de amparo en el que su otorgamiento dependía de forma inmediata del juicio realizado sobre la compatibilidad con la Constitución de un precepto legal preconstitucional ${ }^{29}$.

En resumen, en el momento presente puede considerarse consolidada la doctrina del TC acerca de su competencia para declarar la «inconstitucionali-

22 STC 11/1981, de 8 de abril, Fto. Jco. 2.

${ }^{23}$ Ibid. F Fo. Jco. 4.

${ }^{24}$ STC 14/1981, de 29 de abril, Fto. Jco. 4.

${ }^{25}$ Ibid.

${ }^{26}$ Ibid., Fto. Jco. 3.

${ }^{27}$ Véase infra, 1.2.2.

${ }_{23}^{23}$ STC 34/1981, de 10 de noviembre.

${ }^{2}$ STC 40/1981, de 18 de diciembre. 
dad sobrevenida» del derecho preconstitucional, una competencia que ya no podrá venirle en forma de control abstracto ${ }^{30}$, pero que sí le seguirá viniendo a través del control concreto y del recurso de amparo.

\subsection{La constitucionalidad «interna».}

Tratamos a continuación este problema, por hallarse en estrecha relación con el anterior. En efecto, es un problema privativo del derecho preconstitucional, pero aquí ya no se trata de una cuestión de competencia del TC para conocer acerca del mismo, sino acerca de si cabe proceder con el mismo rigor que el aplicable al derecho posconstitucional. Se trata, ante todo, de un problema de constitucionalidad formal, pero también ofrece la jurisprudencia un caso en el que el problema es de constitucionalidad material.

Comenzando por los primeros, es necesario señalar que la Constitución protege el régimen legal de los derechos fundamentales a través de una serie de previsiones como son, notablemente, la exigencia de ley orgánica ${ }^{31}$ para su regulación, así como la prohibición de que dicha regulación pueda verse afectada por decretos-leyes. Ahora bien, en el proceso de restauración del Estado de Derecho, con anterioridad a la Constitución, se fueron regulando las distintas libertades públicas, ya por ley — por supuesto, ordinaria- ya incluso mediante decreto-ley ${ }^{32}$. ¿Cabía seguir considerando válida esta legislación tras la entrada en vigor de la Constitución?

El problema se le plantea al TC a través de un recurso de inconstitucionalidad del que hemos tenido ocasión de ocuparnos: el relativo al real decreto-ley regulador del derecho de huelga, del año 1977. El TC, que no desea crear lagunas en el ordenamiento, no puede efectuar declaraciones de inconstitucionalidad «sin declaraciones de nulidad»: los estrictos términos en los que se encuentra redactado el artículo 39.1 LOTC parecen impedírselo ${ }^{33}$. En lugar de ello, de un lado, acepta la corrección del recurso al decreto-ley en el año en que éste fue dictado, por lo que no habría motivos para considerar inconstitucional al mismo «por razones referentes a su forma de producción». Ahora bien, de otro lado, el TC advierte que ello «no quiere, en cambio, decir que el real decreto-ley pueda en lo sucesivo considerarse plenamente asimilado a una ley orgánica, ni tampoco que pueda cumplir el papel de la norma de integración a la que la Constitución se remite, pues ésta tendrá que ser siempre una ley orgánica y el legislador, para dar cima al desarrollo de la Constitución, habrá de confeccionar y elaborar esa ley orgánica» ${ }^{34}$.

${ }^{30}$ Dados los estrictos plazos fijados para la interposición de los recursos de inconstitucionalidad.

${ }^{31}$ Véase intra, 2.1.3.

${ }_{32}$ Así, p.e., la Ley 54/1978, de 4 de diciembre, de Partidos Políticos; la Ley 17/ 1976, de 29 de mayo, reguladora del Derecho de Reunión; la Ley 62/1978, de 26 de diciembre, de protección jurisdiccional de los Derechos Fundamentales de la Persona. En situación bastante más delicada - en virtud de la Disposición Transitoria $8 .^{\mathrm{n}} \mathrm{CE}$ - se encuentra el Real Decreto-ley 20/1977, de 18 de marzo, sobre Normas Electorales.

${ }_{33} \mathrm{El}$ precepto dice así: «Cuando la sentencia declare la inconstitucionalidad, declarará igualmente la nulidad de los preceptos impugnados...»

${ }^{34}$ STC 11/1981, de 8 de abril, Fto. Jco. 5. 
El TC, pues, acepta la constitucionalidad formal de estas normas, pero no de modo absoluto e incondicionado, sino sobre la base de que «antes 0 después» el legislador habrá de elaborar la ley orgánica exigida por la Constitución. Hay que reconocer, con todo, la vaguedad de los términos en los que se expresa el TC, que no contribuirán a que el legislador se dé una prisa acuciante en cumplir con este deber.

En todo caso, esta jurisprudencia es aplicable a las distintas leyes y decretos-leyes a que antes nos referíamos y que se encuentran en la misma situación.

Un planteamiento similar al que acabamos de reflejar referido a la inconstitucionalidad formal es el llevado a cabo por el TC con respecto a la legislación preconstitucional relativa al régimen local en la sentencia que ya conocemos, 4/1981, de 2 de febrero. Sólo que en estos supuestos el problema es de inconstitucionalidad material y, concretamente, derivado de la vinculación y fuerza derogatoria de los principios proclamados por la Constitución, en este caso el de la autonomía local. El TC anuncia que su criterio va a ser el de aplicar a la legislación de régimen local, en primer lugar, el principio de interpretación conforme, y en segundo lugar, el de declarar la «inconstitucionalidad sobrevenida» allí donde dicha interpretación conforme sea inviable.

Ahora bien, una vez realizada esta operación, «no por ello podrá afirmarse que la legislación de régimen local se ajusta - de forma positiva- $x$ los principios inspiradores de la Constitución, ya que ha sido dictada con anterioridad a la misma y, por consiguiente, sin poder tener en cuenta tales principios ni, en especial, la nueva distribución del poder prevista en el título VIII de la Constitución. Por ello, debe afirmarse que tal ajuste se producirá cuando el legislador dicte una nueva legislación de régimen local, de acuerdo con el mandato implícito que puede deducirse de los arts. 148.1.2." y 149.1.18. ${ }^{a}$ de la propia Constitución» ${ }^{35}$.

La solución, pues, es bastante similar a la de las situaciones de inconstitucionalidad formal. Ahora bien, teniendo en cuenta que aquí se hallan implicados problemas de fondo, parece razonable exigir al legislador una mayor diligencia en este supuesto ${ }^{36}$.

El TC, finalmente, ha tratado de caracterizar la especial situación de estas normas en la STC 36/1982, en relación con la legislación relativa al derecho de reunión. En efecto, el fundamento jurídico 9 de dicha sentencia las califica de «normas preconstitucionales provisionales», una expresión, a nuestro entender, no del todo correcta, puesto que la «provisionalidad» no se puede decir que afecte en este caso a la vigencia de la norma, sino a su validez o

${ }^{35}$ STC 4/1981, de 2 de febrero, Fto. Jco. 1.

${ }^{36}$ El mantenimiento de esta legislación se complica en virtud de las competencias que las Comunidades Autónomas reciben en esta materia. Véase STC 32/1981, de 28 de julio, Fto. Jco. 6. Cfr. comentario a esta sentencia de M. Sánchez Morón, «Las Comunidades Autónomas y las Provincias (Comentario a la Sentencia del Tribunal Constitucional sobre la Ley de Transferencia de las Diputaciones catalanas a la Generalidad)», en CivitasREDA, 32 (1981), págs. 867-878. Sobre la autonomía municipal en el marco de la Constitución de 1978, cfr. A. Embid Irujo, «Autonomía municipal y Constitución: aproximación al concepto y significado de la declaración constitucional de autonomía municipal», en Civitas-REDA, 30 (1981), págs. 437-470. 
legitimidad, es decir, a su constitucionalidad ${ }^{37}$. De todos modos, la sentencia es importante porque proclama expresamente la situación de interinidad de esta legislación.

\subsection{Las sentencias «interpretativas».}

Las llamadas sentencias «interpretativas» como forma de manifestación acerca de la constitucionalidad de una norma no se hallan previstas en la LOTC ni, muchos menos, en la Constitución; los mismos términos en los que se halla regulado el control de constitucionalidad dan pie incluso a pensar que el legislador no ha contemplado tal posibilidad. La introducción, por tanto, de esta práctica en la jurisprudencia del TC debe ser entendida como una manifestación más de la autonomía de aquél en su función de «intérprete supremo de la Constitución».

En esta materia cabe constatar un cierto grado de contradicción entre la opinión del TC acerca de las «sentencias interpretativas» y su propia actuación. En efecto, la cuestión de las sentencias «interpretativas» tiene entrada en la jurisprudencia del TC con ocasión del recurso planteado contra el Estatuto de Centros Escolares ${ }^{38}$, en el que los recurrentes solicitan expresamente del TC una sentencia «interpretativa». La respuesta del TC en este punto es decididamente restrictiva: se trata de una práctica que se da en otros países a fin de evitar lagunas innecesarias y que el TC considera «un medio lícito, aunque de muy delicado y difícil uso». En cualquier caso, lo que no considera lícito es que «la emanación de una sentencia de este género pueda ser objeto de una pretensión de los recurrentes» ${ }^{39}$.

Muy poco tiempo después, la sentencia 11/1981, de 8 de abril, intenta delimitar el posible alcance de este tipo de sentencias distinguiendo entre un uso restringido de esta técnica en virtud del cual el TC determina en qué sentido o extremo un texto legal puede ser considerado constitucional $(o$, alternativamente, inconstitucional), uso que el TC considera lícito, y un uso amplio o extendido de esta técnica con base en el cual el TC en realidad procedería a la creación o reconstrucción de la norma a partir de una pluralidad de textos legales más o menos próximos o conexos existentes en el ordenamiento. Este último uso de la técnica de la «sentencia interpretativa» no es considerado lícito por parte del TC, que correría peligro de convertirse en legislador «positivo» en sentido estricto ${ }^{40}$.

${ }^{37}$ STC 36/1982, de 16 de junio, Fto. Jco, 9: «... aunque la base de esta resolución sean normas preconstitucionales provisionales, que el legislador debiera sustituir, para que el artículo 21 de la Constitución, regulador del importante derecho de reunión, se complemente por normas orgánicas posconstitucionales, que desarrollen adecuadamente y faciliten lo más posible su realización.»

${ }^{38}$ Cit. nota 16.

${ }^{39}$ STC 5/1981, de 13 de febrero, Fto. Jco. 6.

40 STC 11/1981, de 8 de abril, Fto. Jco. 4. El magistrado del TC, profesor Rubio Llorente, se manifiesta, en un reciente artículo, mucho más abierto a las «sentencias interpretativas», que considera consustanciales a cualquier función jurisdiccional, criticando decididamente la concepción restrictiva del juez constitucional como legislador «negativo»; hay en sus palabras una crítica más o menos velada al mencionado Fto. Jco. de la sentencia $11 / 1981$, de 8 de abril («Sobre la relación entre Tribunal Constitucional y Poder 
El TC, en efecto, no ha llevado a efecto este tipo de sentencias interpretativas «amplias», pero sí viene haciendo un uso frecuente de las «menos amplias». Son usuales las declaraciones de constitucionalidad (o, alternativamente, de inconstitucionalidad) «en cuanto» referidas a un extremo determinado ${ }^{41}$. Más allá de esto, algunas sentencias reflejan en el fallo una labor bastante más recreadora o conformadora de la norma, como ocurre en la STC $22 / 1981$, de 2 de julio ${ }^{42}$. Pero, sobre todo, el TC ha venido usando (y quizá abusando) desde fines de 1981 de la especial técnica interpretativa en virtud de la cual la interpretación considerada constitucional de la norma no aparece incluida en el fallo de la sentencia, el cual se limita a remitirse a la interpretación contenida o desarrollada en los fundamentos jurídicos de la sentencia ${ }^{43}$.

\subsection{Otras formas de inconstitucionalidad.}

La inconstitucionalidad «parcial» de una ley, que aparece contemplada en la misma Constitución en términos criticados por la doctrina ${ }^{44}$, es la única apreciada hasta ahora por el TC en lo que se refiere a normas con rango de ley. Por su parte, la STC 11/1981, de 8 de abril, ha precisado las condiciones de la inconstitucionalidad «por conexión o consecuencia», apreciada por el TC en diversas ocasiones ${ }^{45}$. Es importante la advertencia del TC relativa a la inconstitucionalidad «por omisión» en que puede incurrir el legislador en el supuesto de que éste no dicte las normas de desarrollo de la Constitución ordenadas por esta última ${ }^{46}$.

\subsubsection{Las formas de control de constitucionalidad.}

Como es sabido, el ordenamiento español prevé tanto un control abstracto de constitucionalidad (el llamado «recurso de inconstitucionalidad») como un

Judicial en el ejercicio de la jurisdicción constitucional», en Revista Española de Derecbo Constitucional, 4 [1982], págs. 35-67).

${ }^{41}$ Así, p.e., en las STC 4/1981, de 2 de febrero; 11/1981, de 8 de abril, y 14/1981, de 29 de abril, entre otras.

${ }_{42}$ "Que es inconstitucional la Disposición Adicional 5.a del Estatuto de los Trabajadores, interpretada como norma que establece la incapacitación para trabajar a los sesenta y nueve años y de forma directa e incondicionada la extención de la relación laboral a esa edad.s En este caso, como se ve, lo que el TC fija es la interpretación del precepto, considerada no constitucional.

${ }_{43}$ Así la STC 31/1981, de 16 de noviembre, y la STC 5/1982, de 8 de febrero, en las que existe una remisión genérica a la interpretación contenida en los fundamentos juridicos. En posteriores sentencias, el TC al menos precisa el Fto. Jco. concreto en el que se contiene la interpretación considerada correcta. Así, p.e., en la STC 6/1982, de febrero, entre otras.

${ }^{4} \mathrm{La}$ crítica se dirige a la cláusula inicial del art. $164.2 \mathrm{CE}$ : «Salvo que en el fallo se disponga otra cosa, subsistirá la vigencia de la ley en la parte no afectada por la inconstitucionalidad.» Cfr. F. Rubio Llorente y M. Aragón, «Enunciados aparentemente vacíos en la regulación constitucional del control de constitucionalidad», en Revista de Estudios Políticos, 7 (1979), págs. 161-169.

${ }_{45}$ STC 11/1981, de 8 de abril, Fto. Jco. 27. Así, STC 37/1981, de 16 de noviembre de 1981, Fto. Jco. 4, entre otras.

${ }^{46}$ STC $24 / 1982$, de 13 de mayo, Fto. Jco. 3. 
control concreto de constitucionalidad (la llamada «cuestión de inconstitucionalidad»), todo ello con independencia de algunas figuras a las que se hará referencia más adelante.

\subsection{El control abstracto de constitucionalidad (el «recurso de inconstitucionalidad»).}

La Constitución había previsto un control abstracto de constitucionalidad a iniciativa de una serie de órganos o partes sustanciales de los mismos, cuales eran el Presidente del Gobierno, el Defensor del Pueblo, cincuenta diputados, cincuenta senadores, los órganos ejecutivos de las Comunidades Autónomas y, en su caso, las Asambleas legislativas de las mismas (art. 161.1.a de la CE). La LOTC, por su parte, había realizado una importante precisión respecto de la legitimación de los órganos de las Comunidades Autónomas, en virtud de la cual éstas sólo podrían impugnar la constitucionalidad de una ley del Estado cuando la misma pudiese afectar a su propio ámbito de autonomía ${ }^{47}$. Esta precisión constituía evidentemente una limitación, cuya constitucionalidad ha sido discutida ${ }^{48}$. En todo caso, el TC se ha visto obligado bastante pronto a tomar posición con respecto a este precepto en su sentencia 25/1981, de 14 de julio, recaída en el recurso de inconstitucionalidad planteado por el Parlamento vasco frente a la conocida como «Ley Antiterrorista» ${ }^{49}$.

En esta sentencia, el TC no solamente acepta la constitucionalidad del artículo 28.2 LOTC (que, por lo demás, tampoco los recurrentes impugnan), sino que implícitamente viene a considerar que dicho precepto es el único coherente con la naturaleza del principio de autonomía reconocido por la Constitución. La autonomía, según el TC y en base al artículo $137 \mathrm{CE}$, responde y recibe su sentido de la existencia de unos intereses propios de un determinado ámbito territorial, siendo en base a la existencia de esos intereses como las Comunidades Autónomas reciben unas determinadas competencias. Cualquier actuación de una Comunidad Autónoma no justificada en el ejercicio y la defensa de esas competencias no tendría razón de ser. $\mathrm{Y}$, precisamente, la materia objeto de la ley impugnada - la suspensión individual de derechos fundamentales- se enmarca netamente en el seno del interés general del Estado, sin que al respecto las Comunidades Autónomas detecten competencia alguna.

Esta sentencia, sin embargo, va acompañada de un importante voto particular suscrito por cuatro magistrados en el que, sin cuestionar la constitucionalidad del citado artículo 32.2 LOTC, se propugna una interpretación distinta de los términos de dicho artículo: la expresión «puedan afectar» no

${ }^{47}$ Art. 32.2: «Para el ejercicio del recurso de inconstitucionalidad contra las leyes, disposiciones o actos con fuerza de ley del Estado que puedan afectar a su propio ámbito de autonomía están también legitimados los órganos colegiados ejecutivos y las Asambleas de las Comunidades Autónomas, previo acuerdo adoptado al efecto.»

${ }^{48}$ Cfr. J. Corcuera, "Autonomía y recurso de inconstitucionalidad», en Herri-Arduralarizazko Euskal Aldizkaria. Revista Vasca de Administración Pública, 1 (1981), páginas $193-215$.

${ }^{49}$ Ley Orgánica 11/1980, de 1 de diciembre, dictada en base al artículo $55.2 \mathrm{CE}$. 
se identifica o agota en el ámbito de las competencias de la Comunidad Autónoma (lo que materialmente reduciría esta legitimación a la del conflicto de competencias), sino que comprendería también la defensa de los «intereses públicos» en el ámbito comunitario, por lo que el Parlamento vasco se hallaría legitimado para interponer el recurso en cuestión y el TC obligado a entrar en el fondo del asunto ${ }^{50}$.

Esto por lo que se refiere a la legitimación de las Comunidades Autónomas. Dentro del problema de la legitimación cabría citar también el pronunciamiento del TC en la sentencia $27 / 1981$, de 20 de julio, en la que no considera aplicable a los parlamentarios recurrentes la doctrina de los actos propios: el que un parlamentario haya votado en la Cámara en favor de un precepto no es óbice para que posteriormente pueda suscribir un recurso de inconstitucionalidad contra dicho precepto ${ }^{51}$.

Por lo que hace a la regulación por la LOTC del control abstracto de constitucionalidad, es de destacar el plazo de tres meses a partir de la publicación de la norma para interponer un recurso de inconstitucionalidad. Transcurrido el plazo, el precepto sólo es susceptible de control concreto, o bien con ocasión de otro proceso constitucional. Este precepto es el que daría lugar a la previsión del precepto transitorio que reabría un plazo de dicha duración a partir de la constitución del TC para permitir la impugnación de leyes promulgadas hasta entonces, y del que ya hemos tenido ocasión de ocuparnos.

Por su parte, los plazos de tramitación del recurso fijados por la LOTC resultan excesivamente breves, si bien el TC tiende a cumplirlos con cierta laxitud ${ }^{52}$.

En el período examinado el TC ha resuelto 16 recursos de inconstitucionalidad, seis de ellos a iniciativa de la oposición parlamentaria, nueve a iniciativa del Presidente del Gobierno frente a leyes de las Comunidades Autónomas de Cataluña y del País Vasco y uno a iniciativa de la Comunidad Autónoma del País Vasco. Los recursos de inconstitucionalidad pendientes son casi todos ellos del Presidente del Gobierno frente a leyes de las Comunidades Autónomas de Cataluña y del País Vasco. El recurso de inconstitucionalidad tiende, pues, a convertirse en la manifestación a nivel legislativo de los conflictos de competencia entre el Estado y las Comunidades Autónomas.

\subsection{El control concreto de constitucionalidad (la «cuestión de inconstitucionalidad»).}

Como consecuencia del «monopolio de rechazo» otorgado al TC, la Constitución dispone que: «Cuando un órgano judicial considere en algún proceso que una norma con rango de ley, aplicable al caso, de cuya validez dependa el fallo, pueda ser contraria a la Constitución, planteará la cuestión ante el

50 STC 25/1981, de 14 de julio. Véase infra, 2.3.2.

${ }^{51}$ STC 27/1981, de 20 de julio, Fto. Jco. 9.

${ }^{52}$ Cfr. art. 34 LOTC. De hecho, los recursos de inconstitucionalidad se han resuelto en un plazo aproximado de cinco meses. 
Tribunal Constitucional en los supuestos, en la forma y con los efectos que establezca la ley, que en ningún caso serán suspensivos» (art. 163).

A lo largo de las seis sentencias dictadas en «cuestiones de inconstitucionalidad», el TC ha tenido ocasión de precisar algunos extremos relativos a las mismas. En primer lugar, por lo que hace a la naturaleza de esta forma de control, la misma ha venido precisada por la sentencia $17 / 1981$, de 1 de junio, la segunda en este tipo de procesos de constitucionalidad y que viene a recoger algunas de las ideas ya contenidas en el voto particular que acompañaba a la primera de aquéllas, y que ya hemos tenido ocasión de citar ${ }^{3}$.

Para el TC existe una «identidad teleológica» entre los dos procesos de constitucionalidad, la garantía de la primacía de la Constitución. Ahora bien, si el plazo preclusivo de tres meses fijado para el control abstracto debe conservar algún sentido es preciso que el control concreto no pueda convertirse en una vía para impugnar en abstracto la constitucionalidad de las normas que han dejado de ser susceptibles de tal control. Para ello el TC considera ineludible hacer respetar las condiciones bajo las cuales se le puede someter el control concreto de una determinada norma. En particular es preciso que la norma en cuestión condicione el fallo del tribunal a quo. Cuando esto no se produzca, el TC no deberá pronunciarse. Este era precisamente el caso de la disposición sometida al juicio del TC, la cual todo el mundo está de acuerdo en considerar derogada por la Constitución, pero puesto que la misma no condiciona el fallo, el TC declara que no ha lugar a pronunciarse sobre la misma ${ }^{54}$.

La tercera de las sentencias dictadas en una cuestión de inconstitucionalidad es la única de las dictadas en el año 1981 que tiene por objeto una norma posconstitucional. Es interesante que el TC responde con una sentencia interpretativa, ya citada, que supone el que la disposición impugnada no es de aplicación en el proceso que dio origen a la cuestión de inconstitucionalidad ${ }^{55}$.

La cuarta de las sentencias de este tipo es especialmente interesante por tratarse de una cuestión de inconstitucionalidad que podríamos calificar de «interna», por cuanto originada en el mismo TC, en una de sus Salas, con ocasión de un recurso de amparo, en virtud de lo previsto en el artículo 5.2 LOTC, por lo que nos ocuparemos de ella en el apartado siguiente ${ }^{56}$.

Por lo demás, el TC ha declarado expresamente que es posible plantear una «cuestión de inconstitucionalidad» sobre un precepto que ya ha sido objeto de un «recurso de inconstitucionalidad»; esto tiene interés dada la redacción del artículo 29.2 LOTC, que parecía dar a entender que ello sólo sería posible cuando el recurso de inconstitucionalidad hubiese fracasado por razones de forma ${ }^{5}$.

En conjunto cabe considerar el número de «cuestiones de constitucionalidad» planteadas al TC como anormalmente bajo; el fenómeno, ya apreciable

${ }^{53}$ STC 14/1981, de 29 de abril.

${ }^{54}$ STC 17/1981, de 1 de junio.

55 STC 22/1981, de 2 de julio. Véase supra, nota 42.

${ }^{56}$ STC 34/1981, de 10 de noviembre.

57 STC 4/1981, de 2 de febrero, Fto. Jco. 1. 
en $1981^{58}$, se hace especialmente visible en la primera mitad de $1982^{59}$, sin que el número de cuestiones de inconstitucionalidad pendientes permita apreciar una intensificación de las mismas ${ }^{60}$.

\subsubsection{El recurso de amparo constitucional}

La Constitución encomienda al TC, tras el control de constitucionalidad, y como la segunda de sus competencias, la resolución de los recursos de amparo «por violación de los derechos y libertades referidos en el artículo 53.2 de esta Constitución, en los casos y formas que la ley establezca» (artículo 161.1.b). Estos derechos y libertades son los contenidos en los artículos 14 a 29 CE (más la objeción de conciencia), los cuales constituyen básicamente la tabla de derechos y libertades clásica. Este recurso de amparo constitucional no es, sin embargo, un recurso autónomo, al que quepa acudir directamente ${ }^{61}$, sino que tiene un carácter subsidiario o complementario de la protección otorgada por el Poder Judicial a través de un «amparo judicial» previsto en el artículo 53.2 CE consistente en un «procedimiento basado en los principios de preferencia y sumariedad» ${ }^{62}$. Hasta tanto no se dicte la ley que regule expresamente este «amparo judicial», el mismo es sustituido por las previsiones de la Ley 62/1978, «de protección jurisdiccional de los derechos y libertades de la persona», tal como dispone la Disposición Transitoria 2. ${ }^{a}$ LOTC.

Esta competencia relativa al recurso de amparo constitucional es la única encomendada no al Pleno del TC, sino a alguna de las dos Salas de seis magistrados cada una en las que se divide el TC a estos efectos. De ahí que la LOTC haya previsto una especie de cuestión de inconstitucionalidad «interna», a la que antes nos referíamos, para aquellos supuestos en los que el recurso de amparo se estime «porque la ley aplicada lesiona derechos fundamentales o libertades públicas». En tal supuesto, la Sala dictará sentencia, pero a continuación «elevará la cuestión al Pleno, que podrá declarar la inconstitucionalidad de dicha ley en nueva sentencia», con efectos erga omnes (art. 55.2).

Se trata, pues, de una cuestión de inconstitucionalidad, pero una cuestión de inconstitucionalidad «atípica»: en primer lugar, porque opera en el interior del TC entre una de sus Salas y el Pleno; en segundo lugar, porque la cuestión se plantea una vez que la Sala ha dictado sentencia. Esto lo ha explicado el TC en la única sentencia dictada en virtud del artículo 55.2 LOTC: «La resolución de los recursos de amparo es una competencia de las Salas que no aparece limitada en el supuesto de que la sentencia haya de fundarse

s8 Sólo cuatro sentencias (de un total de 42) tienen por objeto "cuestiones de inconstitucionalidad», de las cuales una de ellas a iniciativa de una de las Salas del mismo TC.

${ }^{59}$ Sólo dos sentencias (de un total de 59 dictadas de enero a julio).

to En los primeros meses de 1982, el Boletín Oficial del Estado no da noticia de la admisión de ninguna cuestión de inconstitucionalidad. Por el contrario, en los últimos meses el TC ha admitido a trámite tres cuestiones de inconstitucionalidad.

${ }^{61}$ Con la excepción, prácticamente única, de la objeción de conciencia (art. 45 LOTC).

62 La subsidiariedad del «recurso de amparo constitucional» es correctamente destacada por Rubio Llorente, cit. nota 40 , págs. 65 y sigs. 
en que la ley aplicada lesiona derechos fundamentales o libertades públicas. Lo que sucede es que el ejercicio de la Sala se circunscribe al caso concreto planteado, por lo que su conocimiento sobre la constitucionalidad de la ley es meramente instrumental y no produce los efectos generales previstos en el artículo 38 de la LOTC.» El sentido del sometimiento de la cuestión al Pleno es el obtener precisamente una declaración con efectos erga omnes ${ }^{63}$.

Especial interés procesal suscita la última de las sentencias en recurso de amparo del año 1981, en la que la estimación de éste se halla inmediatamente condicionado por el juicio que se efectúe acerca de la constitucionalidad de un precepto legal ${ }^{64}$. En este caso, el TC decide excepcionalmente reservar el conocimiento de este recurso al Pleno. Podría pensarse que esta conducta estaría explicada por el hecho de que lo que se va a efectuar es, ante todo, un control de normas y que, de este modo, caso de ser la sentencia estimatoria, no habría necesidad de proceder en los términos del artículo 55.2 LOTC; esto, sin embargo, no podría ser así, pues no es posible declarar la inconstitucionalidad de un precepto sin dar audiencia al Legislativo y al Ejecutivo (art. 37.2 LOTC). Debe entenderse, más bien, que el TC ha reservado este recurso de amparo al Pleno porque en él se va a sentar una jurisprudencia importante relativa a la legitimación para impugnar la constitucionalidad de una ley a través del recurso de amparo ${ }^{65}$.

La doctrina del TC a este respecto es la de que, si bien «en el amparo constitucional no pueden hacerse valer otras pretensiones que las dirigidas a restablecer o preservar los derechos o libertades por razón de los cuales se formuló el recurso», una interpretación racional del artículo 55.2 LOTC debe conducir a la conclusión de que si la violación alegada tiene su base en un precepto legal, la inconstitucionalidad del mismo puede ser objeto de alegación por el recurrente: «De este modo puede admitirse una pretensión directa de inconstitucionalidad sostenida por particulares, aunque limitada a las leyes que lesionen o coarten los derechos y libertades reconocidos en los artículos 14 a 30 de la Constitución, y a los casos en que el recurrente haya experimentado una lesión concreta y actual en sus derechos y siempre que sean inescindibles el amparo constitucional y la constitucionalidad de la ley» ${ }^{66}$.

A través de esta jurisprudencia, y con las limitaciones en la misma contenidas, el TC reconoce a los particulares la posibilidad de impugnar la constitucionalidad de una ley a través de un recurso de amparo, y no ya solamente a través de la vía de la cuestión de inconstitucionalidad. Siendo esto así, quizá fuera lo más lógico el establecer un mecanismo similar al previsto para las cuestiones de competencia que se revelaren tienen su origen en un precepto legal, en cuyo caso la cuestión se tramita como recurso de inconstitucionalidad $^{\sigma}$. Ello, sin embargo, exigiría una reforma de la LOCT.

${ }^{63}$ STC 34/1981, de 10 de noviembre, Fto. Jco. 1.

${ }^{64}$ STC 40/1981, de 18 de diciembre.

65 Ello parece venir confirmado por el otro supuesto en el que el Pleno del TC se ha reservado la resolución de un recurso de amparo, la STC 12/1982, de 13 de marzo, relativa a la legitimidad del monopolio público de la televisión.

${ }^{66}$ STC 40/1981, de 18 de diciembre, Fto. Jco. 1.

67 Art. 67 LOTC: «Si la competencia controvertida hubiera sido atribuida por una ley o norma con rango de ley, el conflicto de competencias se tramitará desde su inicio o, 
Los «recursos de amparo constitucional» absorben las dos terceras partes de las sentencias dictadas (67 sobre 101). A su vez, de estas 67 sentencias más de la mitad de las mismas (38 aproximadamente) tiene por objeto del amparo el «derecho a la jurisdicción» en alguna de sus variantes contenido en el artículo $24 \mathrm{CE}$ : a este respecto, el TC ha debido ante todo dejar absolutamente claro que el amparo del derecho a la jurisdicción no le convierte en una última instancia; su misión se agota en el eventual restablecimiento del recurrente en las garantías procesales, sin que se le pueda exigir que entre a conocer del fondo del asunto ${ }^{68}$. Tras el «derecho a la jurisdicción», el amparo que con mayor frecuencia ha debido ocupar al TC ha sido el «principio de igualdad» contenido en el artículo $14 \mathrm{CE}$ (aproximadamente 20 sentencias sobre un total de 67). Cuantitativamente los demás derechos amparados por el TC quedan muy por debajo de los dos anteriores, si bien el TC ha efectuado pronunciamientos de importancia respecto a la libertad de expresión $^{69}$ o la objeción de conciencia ${ }^{70}$, entre otras, a través del «recurso de amparo constitucional».

En opinión de Rubio Llorente, el carácter subsidiario del recurso de amparo constitucional tespecto de la protección de los derechos fundamentales, que corresponde básicamente al Poder Judicial, unido al perfeccionamiento de las técnicas procesales de garantía de estos derechos, debe permitir o posibilitar una evolución en la función del recurso de amparo constitucional: su auténtica función sería entonces la de «instrumento para precisar, definir y, en cuanto sea necesario, redefinir continuamente el contenido de los derechos fundamentales»; ello, sin embatgo, sólo sería plenamente posible cuando el Poder Judicial se encuentre en situación de garantizar el ejercicio de los derechos fundamentales mediante un eficaz sistema de recursos ${ }^{71}$.

\subsubsection{Los conflictos de competencia}

La Constitución confía al TC, como la tercera de sus competencias, el conocimiento de «los conflictos de competencias entre el Estado y las Comunidades Autónomas o de los de éstas entre sí» (art. 161.1 CE). La LOTC ha distinguido entre conflictos «positivos» de competencias y conflictos «negativos» de competencias, entendiendo por estos últimos aquellos supuestos en los que ninguno de estos entes reconoce detentar una competencia determinada. Hasta el presente todos los conflictos de competencia planteados y resueltos han sido conflictos «positivos» de competencia; todos ellos se han desarrollado entre el Estado y una Comunidad Autónoma, ninguno entre Comunidades Autónomas; las dos únicas Comunidades Autónomas que han protagonizado estos conflictos han sido las de Cataluña y del País Vasco, por ser las dos únicas constituidas hasta fines de 1981.

en su caso, desde que, en defensa de la competencia ejercida, se invocare la existencia de la norma legal habilitante, en la forma prevista para el recurso de inconstitucionalidad.»

${ }_{68}$ Así, entre otras muchas, la STC 32/1981, de 28 de julio.

*9 Así, la citada STC 12/1982, relativa a la televisión.

to En especial, la primera de las sentencias dictadas en esta materia: STC 15/1982, de 30 de abril.

${ }^{7}$ Cit. nota 40 , págs. 65 y sigs. 
A pesar de que la primera sentencia en un conflicto de competencias no se dicta hasta el 5 de noviembre de 1981, siendo la única dictada por el TC sobre estos procesos en dicho año, los conflictos de competencia han alcanzado un enorme desarrollo, de tal modo que en los primeros siete meses de 1982 se han dictado 11 sentencias sobre los mismos (de un total de 59). El examen de los asuntos pendientes de sentencia viene a confirmar el actual protagonismo de los conflictos de competencia en el trabajo del TC, sólo superado por los «recursos de amparo constitucional». Este dato debe ser puesto en conexión con el fenómeno ya indicado de que la mayoría de los recursos de inconstitucionalidad tienen por objeto las competencias legislativas de las Comunidades Autónomas.

La importancia que han adquirido estos conflictos de competencia era previsible dados los múltiples problemas de interpretación que suscita cualquier sistema de distribución de competencias entre poderes públicos, acentuado, si cabe, por las especiales dificultades de interpretación del título VIII de la Constitución española y de los Estatutos de Autonomía, en especial los dos primeros (País Vasco y Cataluña). A este respecto, es de esperar que la jurisprudencia surgida de los conflictos del Estado con estas dos Comunidades Autónomas haga posible unas relaciones iniciales menos conflictivas entre el Estado y la mayoría de las restantes Comunidades Autónomas constituidas en los últimos doce meses.

Las competencias objeto de conflicto hasta el presente han sido bastante variadas: por razón de su frecuencia cabe destacar las relativas a materia laboral y funcionarios públicos ${ }^{72}$, si bien el TC ha debido pronunciarse también ya acerca de tales materias como el régimen de la radiodifusión ${ }^{73}$, educación ${ }^{74}$, sanidad ${ }^{75}$, ordenación del crédito $^{76}$, entre otras. De todos modos, ésta es una materia que no cabe tratar más que en íntima conexión con la jurisprudencia contenida en los «recursos de inconstitucionalidad» relativos a las competencias legislativas de las Comunidades Autónomas, que es la que viene estableciendo los criterios interpretativos básicos aplicables a los conflictos de competencias propiamente dichos ${ }^{\pi}$.

\subsubsection{Otros procesos constitucionales}

Agrupamos en este apartado una serie de competencias en las que el TC no ha dictado aún ninguna sentencia.

1.2.4.1. El artículo 161.2 CE: las «impugnaciones del Gobierno» y su eficacia suspensiva.

El artículo $161 \mathrm{CE}$, tras recoger en un primer apartado las competencias del TC que acabamos de comentar, contiene un segundo apartado redactado

7 En materia laboral cabe destacar la sentencia 33/1981, de 5 de noviembre, y las sentencias núms. 18, 48 y 57 de 1982. En materia de funcionarios públicos cabe destacar las sentencias núms. 54 y 57 de 1982.

${ }_{73}$ STC 26/1982, de 24 de mayo, y STC 44/1982, de 8 de julio.

74 STC 6/1982, de 22 de febrero.

${ }^{75}$ STC 3/1982, de 8 de febrero.

${ }^{76}$ STC $1 / 1982$, de 28 de enero.

$\pi$ Así, p.e., las sentencias 32/1981, de 28 de julio, y 37/1981, de 16 de noviembre. 
en los siguientes términos: «El Gobierno podrá impugnar ante el Tribunal Constitucional las disposiciones y resoluciones adoptadas por los órganos de las Comunidades Autónomas. La impugnación producirá la suspensión de la disposición o resolución recurrida, pero el Tribunal, en su caso, deberá ratificarla o levantarla en un plazo no superior a cinco meses.»

$\mathrm{El}$ artículo 161.2 CE parecía constituirse, pues, en un cauce abietto al Gobierno, al margen del control de constitucionalidad de las leyes y al margen de los conflictos de competencia, para impugnar cualquier disposición o resolución que no se resolviera a través de los procesos constitucionales anteriores. La LOTC, por su parte, regularía este proceso en un título específico, el título V: «De la impugnación de disposiciones sin fuerza de ley y resoluciones de las Comunidades Autónomas, prevista en el artículo 161.2 de la Constitución». Se precisa, pues, aquí que quedan excluidas de este proceso las disposiciones con fuerza de ley; de otra parte (art. 77), se indica que la impugnación, cualquiera que fuera su base, es decir, aunque no consistiera en un conflicto de competencia, seguirá las normas de procedimiento previstas para aquéllas.

Pues bien, tal procedimiento específico, sin conexión ni con el control de las leyes de las Comunidades Autónomas ni con un conflicto de competencias, no ha sido objeto aún de ninguna sentencia del TC ${ }^{78}$. Ahora bien, la LOTC se ha basado en este precepto 161.2 CE para extender el privilegio de la suspensión concedido en el mismo a favor del Gobierno de la nación tanto a los recursos de inconstitucionalidad como a los conflictos de competencia.

En efecto, de una parte, el artículo 30 LOTC precisa que la admisión de un recurso de inconstitucionalidad no suspenderá la vigencia o aplicación de la ley, «excepto en el caso de que el Gobierno se ampare en lo dispuesto por el artículo 161.2 de la Constitución». Esto es algo que el Gobierno ha hecho hasta ahora generalmente, de tal modo que la impugnación de una ley de una Comunidad Autónoma suele ir acompañada de la suspensión de la misma.

De otra parte, por lo que hace a los conflictos de competencia, el artículo 64.2 LOTC ha dispuesto que si el Gobierno invoca el artículo 161.2 CE, la formalización del conflicto suspenderá inmediatamente la disposición o resolución recurrida. También es esto algo que el Gobierno hace invariablemente cada vez que plantea un conflicto de competencia.

Una cuestión de interés a este respecto es cómo debe interpretarse este plazo de cinco meses: ¿debe entenderse como un plazo máximo para dictar sentencia o debe entenderse que el mismo únicamente obliga al TC, al cumplirse los cinco meses, a decidir sobre la suspensión? Parecía entenderse, aunque la dicción no fuera muy correcta, que sería la sentencia del TC dictada en el plazo de cinco meses la que decidiría el destino de la disposición o resolución impugnada ${ }^{79}$. Es el art. 77 LOTC el que viene a precisar que dicha decisión del TC no tiene por qué coincidir con la sentencia, que puede producirse después. Ello, sin embargo, contradice con los plazos contenidos en

${ }^{78}$ Hay, sin embargo, ya dos «impugnaciones» pendientes de sentencia. Cfr. Boletin Oficial del Estado de 1 de junio y de 30 de julio de 1982

${ }_{79}$ Así, p.e., parece entenderlo Faller, cit. nota 1, pág. 286. 
la LOTC, que imponen de hecho unos plazos de tramitación del recurso normalmente inferiores a los cinco meses.

Por lo que hace a la práctica del TC, éste suele prorrogar la suspensión de la disposición o acto objeto del conflicto de competencias cuando se cumplen cinco meses sin haber dictado sentencia. Por lo que hace a las leyes de las Comunidades Autónomas objeto de un «recurso de inconstitucionalidad», el TC ha procurado hasta ahora dictar sentencia dentro del plazo de cinco meses, si bien en tres ocasiones ha ratificado la suspensión al no haber dictado sentencia dentro de dicho plazo ${ }^{80}$.

\subsubsection{Declaración sobre la constitucionalidad de un tratado internacional.}

El artículo 95.2 CE contiene una modalidad de control previo de constitucionalidad relativa a los tratados internacionales en virtud de la cual, y antes de la celebración de un tratado, el Gobierno o alguna de las dos Cámaras pueden requerir al TC para que emita una «declaración» acerca de la constitucionalidad de dicho tratado. Esta modalidad de control, desarrollada en el artículo 78 LOTC, no ha tenido ocasión de ser utilizada hasta el presente.

\subsubsection{El control previo de constitucionalidad de los Estatutos de Autonomía y demás leyes orgánicas.}

Este proceso constitucional no se hallaba previsto por la Constitución, habiendo sido introducido a través de la LOTC en base al artículo 161.1.d de la $\mathrm{CE}$, que permite ampliar las competencias del TC a través de una ley orgánica, como lo era, precisamente, la LOTC ${ }^{81}$. La introducción de esta modalidad preventiva de control de constitucionalidad en un sistema de control esencialmente represivo como es el configurado por la Constitución fue bastante debatido, tanto durante la discusión parlamentaria de la LOTC como por parte de la doctrina ${ }^{82}$. Cuando parecía que este procedimiento de control iba a carecer de relevancia, pues no había sido utilizado ni frente a ningún proyecto de Estatuto de Autonomía ni frente a ningún proyecto de ley orgánica, su utilización en el más polémico de los proyectos de ley desde la aprobación de la Constitución ha conferido un inesperado protagonismo a esta modalidad de control. En efecto, el 3 de agosto de 1982 el TC admitía a trámite cinco recursos previos de inconstitucionalidad frente al proyecto de «Ley Orgánica de Armonización del Proceso Autonómico» (LOAPA), aprobado por las Cámaras, quedando suspendida su sanción y promulgación hasta la sentencia del TC ${ }^{83}$.

${ }^{80}$ Recurso correspondiente a la STC 10/1982 y recursos correspondientes a la Ley del

País Vasco 10/1981 y Ley de Cataluña 12/1981, ambos pendientes de sentencia.

${ }^{81}$ Art. 79 LOTC

${ }^{82}$ Cfr. P. Cruz Villalón, «El control previo de constitucionalidad», en Revista de Derecho Público, 82 (1981), págs. 5-21.

${ }^{83}$ Han presentado estos recursos los Parlamentos y Gobiernos de las Comunidades Autónomas de Cataluña y el País Vasco, así como 50 diputados. Cfr. Boletín Oficial del Estado del día 5 de agosto de 1982. 


\subsubsection{Los conflictos entre órganos constitucionales del Estado.}

$\mathrm{Al}$ igual que en el supuesto anterior, se trata de una competencia no prevista en la Constitución, sino introducida a través de la LOTC, e igualmente discutida por lo que podía suponer de desvirtuación en el funcionamiento del régimen parlamentario ${ }^{84}$. Protagonistas de estos conflictos pueden ser exclusivamente el Congreso de los Diputados, el Senado, el Gobierno de la nación y el Consejo General del Poder Judicial. Hasta el presente no se ha formalizado ningún conflicto de esta naturaleza.

\subsection{Algunos aspectos de la actuación del Tribunal Constitucional}

\subsubsection{Los votos particulares}

La posibilidad de que los miembros del TC expresen su opinión disidente a través de «votos particulares» se halla contenida en la misma Constitución (art. 164.1.1). Esta posibilidad fue vista negativamente por algún sector de la doctrina, que recomendó una regulación que impidiese la publicación de los nombres de los autores de tales votos. La experiencia del Tribunal de Garantías Constitucionales de la II República aconsejaría una cautela de este tipo ${ }^{85}$. La LOTC (art. 90.2), sin embargo, no impuso ninguna cautela semejante, siendo ya posible ofrecer un primer balance acerca de este punto.

Los votos particulares han sido relativamente numerosos durante 1981, año en el que se ha emitido un total de doce votos particulares en torno a diez sentencias. Bastante más excepcionales están resultando los votos particulares en 1982, donde se llevan emitidos sólo cuatro votos particulares en torno a tres sentencias.

La experiencia de los votos particulares puede calificarse como muy positiva: temas tan importantes como los del control sobre el derecho "preconstitucional», el ámbito de la «ley orgánica», la legitimación de los órganos de las Comunidades Autónomas en el recurso de inconstitucionalidad o el principio de igualdad, entre otros, se han visto entiquecidos por las aportaciones de los puntos de vista contenidos en los votos particulares. Es muy interesante comprobar, por lo demás, cómo en algunos casos la opinión contenida inicialmente en un voto particular es adoptada por el TC en una sentencia posterior ${ }^{86}$.

Debe resaltarse en este contexto la actitud del Presidente del TC, que se ha abstenido de emitir hasta el presente voto particular alguno. Esta conducta supone posiblemente un reforzamiento de la auctoritas del Presidente para el

Arts. 73-75 LOTC.

${ }^{83}$ Cfr. G. Trujillo, «Juicio de legitimidad e interpretación constitucional: Cuestiones problemáticas en el horizonte constitucional español», en Revista de Estudios Políticos 7 (1979), págs 145-159.

${ }^{86}$ Así la STC 17/1981, de 1 de junio, en relación con el voto particular a la STC $14 / 1981$, de 29 de abril, acerca de la función de la cuestión de inconstitucionalidad. Igualmente, la STC $37 / 1981$, de 16 de noviembre, en relación con el segundo voto particular a la STC 5/1981, de 13 de febrero, acerca de la potestad legislativa de las Comunidades Autónomas en materias relacionadas con derechos fundamentales. 
supuesto en que hubiera de hacer uso de su «voto de calidad» para dirigir un empate de votos (art. 90.1 LOTC).

\subsubsection{El estilo de las sentencias}

El TC ha abandonado el estilo marcadamente rígido de las sentencias de los órganos del Poder Judicial (los tradicionales «resultandos» y «considerandos»), sustituyéndolo por un estilo más discursivo, flexible $\mathrm{y}$, en definitiva, más acorde con la función de «pedagogía constitucional» que, sin duda, corresponde a la jurisprudencia del TC. Ello se ha considerado, en general, positivo, aunque no haya faltado alguna voz discrepante señalando posibles inconvenientes ${ }^{87}$.

\subsubsection{La potestad reglamentaria del Tribunal Constitucional}

El artículo 2.2 LOTC confiere al TC la potestad de «dictar reglamentos sobre su propio funcionamiento y organización, así como sobre el régimen de su personal y servicios, dentro del ámbito de la presente Ley». En base a esta potestad el TC dictó, ante todo, un reglamento de organización y personal de 15 de enero de 1981. Muy recientemente ha debido dictar normas complementarias sobre la tramitación del recurso previo de inconstitucionalidad ${ }^{88}$, así como sobre el funcionamiento del TC en período de vacaciones ${ }^{p 9}$.

\section{LA INTERPRETACION DE LA CONSTITUCION}

Resulta prácticamente imposible resumir en el ámbito de este informe la labor de «concretización» de la Constitución española realizada por el TC a través de su primer centenar de sentencias. A pesar de ello cabe destacar las manifestaciones más expresivas del TC en torno a los tres capítulos fundamentales de la interpretación de la Constitución de 1978: el ordenamiento jurídico, los derechos fundamentales y las Comunidades Autónomas.

\subsection{El ordenamiento jurídico}

La Constitución española de 1978 ha modificado decididamente el sistema de fuentes del derecho mediante la introducción de dos figuras: los Estatutos de Autonomía y las leyes orgánicas. Pero el TC ha tenido ocasión de pronunciarse ya sobre otros tipos de normas y, ante todo, sobre la Constitución misma.

87 Cfr. T. R. Fernández, Las leyes orgánicas y el bloque de la constitucionalidad, Madrid, 1981, págs. 88-89. Para Tomás Ramón Fernández, el tradicional lenguaje judicial es el más adecuado para asegurar la necesaria concisión y el necesario rigor conceptual.

${ }_{88}$ Acuerdo de 14 de julio de 1982 (Boletín Oficial del Estado de 19 de julio).

${ }^{89}$ Acuerdo de 15 de junio de 1982 (Boletín Oficial del Estado de 2 de julio). 


\subsubsection{La Constitución como norma jurídica}

Ya hubo ocasión de señalar cómo para el TC la Constitución es la lex superior, desde el momento en que hubo de definir su propia función - valedor del principio de constitucionalidad-, así como solventar el problema del derecho preconstitucional. Para el TC, en efecto, y como no podía ser de otra forma, la Constitución es la norma suprema del ordenamiento jurídico, en sus propias palabras, «la norma fundamental y fundamentadora del ordenamiento jurídico» ${ }^{90}$. Consecuencia de ello es su capacidad de vincular a todos los poderes públicos, vinculación general que se extiende a los poderes del Estado «como totalidad» y a los poderes públicos autonómicos ${ }^{91}$.

Pero esta fuerza vinculante de la Constitución no es sólo general por lo que hace a sus destinatarios, sino que también es general por lo que hace a su contenido. En efecto, en la Constitución no cabe distinguir entre un contenido «preceptivo» y un contenido «programático»: la Constitución vincula toda ella por igual, lo que supone que todos sus preceptos son «origen inmediato de derechos y obligaciones», incluidos los principios constitucionales, que participan de la fuerza derogatoria de la Constitución ${ }^{92}$.

De otro lado, la Constitución, con ser una norma jurídica y la primera de ellas, no es una norma como las demás: la Constitución es «una norma cualitativamente distinta de las demás, por cuanto incorpora el sistema de valores esenciales que ha de constituir el orden de convivencia política y de informar todo el ordenamiento jurídico» ${ }^{93}$. Con ello, el TC se distancia de una concepción estrictamente positivista, por lo demás ausente de la misma Constitución. Consecuencia de esta concepción de la norma fundamental es la procedencia de la interpretación finalista como método hermenéutico: «La Constitución incorpora un sistema de valores cuya observancia requiere una interpretación finalista de la norma constitucional» ${ }^{94}$.

\subsubsection{Los Estatutos de Autonomía}

En el marco de la operación de descentralización política del Estado posibilitada y puesta en marcha por la Constitución de 1978, ésta ha creado una categoría de norma inmediatamente subordinada a la Constitución y sustraída a la disponibilidad del legislador. Las normas estatutarias sólo pueden ser modificadas mediante el procedimiento de reforma de los Estatutos, el cual requiere el consentimiento de la Comunidad Autónoma afectada ${ }^{95} \mathrm{o}$, naturalmente, como resultado de una reforma de la Constitución misma. Sólo los artículos 150.3 y $155 \mathrm{CE}$ permiten unos supuestos muy excepcionales de

90 STC 9/1981, de 31 de marzo, Fto. Jco. 3. Jco. 5 .

${ }^{21}$ STC 21/1981, de 15 de junio, Fto. Jco. 17, y STC 32/1981, de 28 de julio, Fto. ${ }_{92}$ STC 4/1981, de 2 de febrero, Fto. Jco.
Jco. 17 .
${ }_{93}$ STC 9/1981, de 31 de marzo, Fto. Jco. 3.

4 STC 18/1981, de 8 de junio, Fto. Jco. 2.

${ }_{95} \mathrm{Si}$ bien la Constitución sólo exige referéndum de ratificación de los proyectos de modificación de los Estatutos de Autonomía especiales (art. $151 \mathrm{CE}$ ), de hecho se ha extendido este requisito a los Estatutos de Autonomía ordinarios (art. 143 CE). 
modificación de la vigencia de los preceptos estatutarios sin intervención de la Comunidad Autónoma afectada. Sin duda será la sentencia pendiente relativa a los recursos previos de inconstitucionalidad interpuestos contra el proyecto de Ley Orgánica de Armonización del Proceso Autonómico (la llamada LOAPA) la que fije la doctrina del TC acerca de la posición de los Estatutos de Autonomía en el ordenamiento jurídico español ${ }^{\%}$. Con independencia de ello, los Estatutos de Autonomía ya han debido jugar un importante papel en la función interpretadora del TC cada vez que se ha tratado de un problema de competencias de una Comunidad Autónoma: en efecto, dado que dichas competencias no se derivan directamente de la Constitución, sino del Estatuto de Autonomía - dentro del marco posibilitado por la Constitución-, el TC ha debido utilizar ante todo el correspondiente precepto estatutario como sujeto o parámetro de la legitimidad de una determinada competencia.

\subsubsection{Las leyes orgánicas}

Con respecto a esta novedad de la Constitución de $1978^{97}$, la doctrina tendió a dividirse inicialmente entre quienes propugnaron una concepción formal de la ley orgánica --es decir, una categoría normativa intermedia entre la Constitución y la ley-, con base en la mayoría cualificada exigida para su aprobación o derogación, y quienes propugnaban una concepción material o competencial de las mismas, dado que la Constitución prevé esta figura para una serie de materias concretas y determinadas, no utilizable discrecionalmente por el legislador para regular cualquier materia. Esta interpretación competencial, que va haciéndose dominante, tropezaba con un precepto de la LOTC que parecía convertir a las leyes orgánicas en una categoría «abierta» ${ }^{98}$. El problema viene sobre todo determinado por la indeterminación de la cláusula «Son leyes orgánicas las relativas al desarrollo de los derechos fundamentales $y$ de las libertades públicas...» (art. 81.1 CE) ${ }^{99}$.

El TC se ha pronunciado básicamente en favor de la tesis competencial, es decir, por la ilegitimidad de una extensión de la ley orgánica a otras materias que no sean las taxativamente previstas en el artículo $80.1 \mathrm{CE}^{100}$. De

"Cfr. Boletin Oficial de las Cortes Generales. Senado. I Legislatura. Serie II, 284 (a), de 6 de julio de 1982 .

${ }^{7}$ Art. $81 \mathrm{CE}$ : «1. Son leyes orgánicas las relativas al desarrollo de los derechos fundamentales y de las libertades públicas, las que aprueben los Estatutos de Autonomía y el régimen electoral general y las demás previstas en la Constitución.-2. La aprobación, modificación o derogación de las leyes orgánicas exigirá mayoría absoluta del Congreso, en una votación final sobre el conjunto del proyecto.»

$\$$ El art. 28.2 LOTC prevé que el TC pueda declarar la inconstitucionalidad de una ley no orgánica que modífique o derogue una ley orgánica «cualquiera que sea su contenidos.

${ }^{9}$ Cfr. F. J. Bastida, «Comentario bibliográfico sobre la naturaleza jurídica de las leyes orgánicas», en Revista Española de Derecho Constitucional, 2 (1981), págs. 285-311.

${ }_{100}$ STC 5/1981, de 13 de febrero, Ftos. Jcos. 20-25. La doctrina, sin embargo, ha detectado contradicciones en la jurisprudencia sentada en esta sentencia. Cfr. T. R. Fernández, cit. nota 87, págs. 87-95. Acerca de esta sentencia, cfr. J. Nicolás Muñiz, «Bestand und Bedeutung der Grundrechte im Bildungsbereich in Spanien», en EuGRZ 8 (1981) págs. 704711 . 
otra parte, por lo que se refiere a las normas de desarrollo de los derechos fundamentales, el TC ha declarado que sólo aquellas que supongan el desarrollo «directo» de un derecho fundamental requieren la forma de ley orgánica: de otro modo se correría el peligro de configurar un ordenamiento integrado mayoritariamente por leyes orgánicas, dado que es difícil hallar alguna materia que no se encuentre en relación más o menos lejana con un derecho fundamental ${ }^{101}$.

\subsubsection{La ley}

Ante todo es preciso señalar cómo el TC se considera a sí mismo no solamente como «defensor de la Constitución, sino defensor también de la ley». En efecto, esta y no otra sería en definitiva la razón de ser del «monopolio de rechazo» detentado por el TC: el impedir que los miembros del Poder Judicial inapliquen discrecionalmente las leyes posconstitucionales que consideren contrarias a la Constitución ${ }^{102}$.

Posiblemente el principio de mayor trascendencia relativa a la ley establecido por el TC sea el referente a su irretroactividad. El TC sienta la doctrina de que si bien el ordenamiento jurídico normalmente establece relaciones «pro futuro», no puede evitar incidir en situaciones originadas con anterioridad: de ahí la procedencia de una interpretación restrictiva del principio de irretroactividad, limitada a las «disposiciones sancionadoras no favorables o en la medida en que restrinja derechos individuales» ${ }^{103}$.

EI TC, por lo demás, ha tenido ocasión de realizar una serie de advertencias atinadas acerca de la perfección técnica de las leyes, de cuyo juicio no se considera competente ${ }^{104}$, acerca de la técnica «reiterativa» presente en determinadas leyes, que reproducen textos insertos en normas de rango superior ${ }^{105}$, acerca de la fuerza no vinculante de los preámbulos de las leyes ${ }^{106}$, entre otras.

\subsubsection{Otras categorías normativas}

El TC ha tenido ocasión de manifestarse ya acerca de otras categorías normativas como los «decretos-leyes», los «decretos legislativos» o los «reglamentos».

${ }^{101}$ STC 6/1982, de 22 de febrero, Fto. Jco. 6.

102 STC 17/1981, de 1 de junio, Fto. Jco. 1.

${ }_{100}$ STC de 20 de julio de 1981, Fto. Jco. 10, y STC 8/1982, de 4 de marzo, Fto. Jco. 3. Cfr. F. López Menudo, «La irretroactividad de las leyes en la Constitución de 1978 (Comentario a la Sentencia del Tribunal Constitucional de 20 de julio de 1981)», en Civitas-REDA, 31 (1981), págs. 718-728.

${ }_{104}$ STC 27/1981, de 16 de noviembre, Fto. Jco. 2, entre otras. Fto. Jco. 6.

${ }^{105}$ STC 40/1981, de 18 de diciembre, Fto. Jco. 1, y STC 38/1982, de 22 de junio,

${ }_{100}$ Sin embargo, «son un elemento importante a tener en cuenta en la interpretación de las leyes», por lo que el TC se considera en la situación de declarar que las manifestaciones del Preámbulo relativas a un precepto declarado nulo «carecen de valor interpretativo alguno» (STC 36/1981, de 12 de noviembre, Fto. Jco. 7). 
La Constitución permite al Gobierno dictar normas con fuerza provisional de ley («decretos-leyes») «en caso de extraordinaria y urgente necesidad» ${ }^{107}$. El TC ha precisado que es competente para comprobar la existencia de este elemento de «extraordinaria y urgente necesidad»; en el único supuesto de control de este tipo de normas ha dejado, sin embargo, un amplio margen de discrecionalidad al Gobierno y al Congreso de los Diputados en orden a la valoración de la presencia de este requisito ${ }^{108}$. El TC se ha declarado igualmente competente para controlar la constitucionalidad de los «decretos legislativos», con independencia de la existencia de otras formas de control de los mismos ${ }^{109}$. Por lo que hace a la potestad reglamentaria del Gobierno, y prescindiendo aquí de los conflictos de competencia entre el Estado y las Comunidades Autónomas en materia de reglamentos, cabe destacar la manifestación del TC acerca del carácter «radicalmente limitado» de dicha potestad reglamentaria frente al carácter «potencialmente ilimitado (dentro de la Constitución)» de la potestad legislativa; concretamente, la potestad reglamentaria sólo cabe en el marco de una autorización o habilitación legislativa «salvo muy contadas excepciones» ${ }^{110}$.

\subsection{Los derechos fundamentales}

«Nada que concierna al ejercicio por los ciudadanos de los derechos que 1a Constitución les reconoce podrá considerarse nunca ajeno a este Tribunal», ha declarado el TC en su sentencia 26/1981, de 17 de julio ${ }^{111}$. En este apartado destacaremos algunos criterios generales de interpretación de los derechos fundamentales desarrollados por el TC como garante supremo de los mismos.

\subsubsection{La naturaleza de los derechos fundamentales}

La doctrina del TC sobre esta materia se halla desarrollada especialmente en la STC 25/1981, de 14 de julio, en el recurso sobre la «Ley Antiterrorista»: es aquí donde el TC asume la teoría del «doble carácter» de los derechos fundamentales, a fin de destacar, ante todo, su aspecto institucional, su función integradora en el Estado de Derecho: «... Establecen, por así decirlo,

${ }^{107}$ Art. $86 \mathrm{CE}$.

${ }^{108}$ Este margen de discrecionalidad, sin embargo, tiene sus límites, y así el TC declara nulo un precepto del «decreto-ley» por el que se delega al Gobierno la facultad para regular en el futuro una materia sometida a reserva de ley: «... las medidas requeridas para hacer frente a una situación de extraordinaria y urgente necesidad han de ser concretas $\mathrm{y}$ de eficacia inmediata $\mathrm{y}$, por tanto, dado su carácter, no pueden alterar la estructura del ordenamiento...» (STC 29/1982, de 31 de mayo, Fto. Jco. 6).

${ }_{109}$ Cfr. arts. 82-85 CE. STC 51/1982, de 19 de julio, Ftos. Jcos. 1 y 2.

110 STC $35 / 1982$, de 14 de junio, Fto. Jco. 2. Por lo demás, el TC ha tenido pronto ocasión de reiterar que el control de la legalidad de los reglamentos corresponde a los jueces y tribunales ordinarios integrantes del Poder Judicial y culminando en la jurisdicción del «Tribunal Supremo» (STC 20/1981, de 11 de junio, Fto. Jco. 1).

${ }^{11}$ Fto Jco. 14. 
una vinculación directa entre los individuos y el Estado y actúan como fundamento de la unidad política sin mediación alguna» ${ }^{12}$.

Es también expresiva, en este contexto, la doctrina sentada por el TC en su sentencia 11/1981, de 8 de abril, al precisar el significado de la sustitución del concepto de «libertad» por el concepto de «derecho» en materia de derechos fundamentales. Así, por lo que hace al «derecho de huelga», que es el derecho examinado, el que el constituyente haya empleado el término de «derecho» y no el de «libertad» significa que no se trata solamente de «establecer, frente a las anteriores normas prohibitivas, un marco de libertad de huelga»: el que la Constitución reconozca un «derecho» de huelga significa que «determinadas medidas de presión de los trabajadores frente a los empresarios son un derecho de aquéllos» ${ }^{113}$.

\subsubsection{El «contenido esencial» de los derechos fundamentales}

El concepto de «contenido esencial», que la CE ha tomado de la Ley Fundamental de Bonn, ha sido bastante pronto objeto de la jurisprudencia del TC. Si bien el concepto aparece utilizado en la sentencia 5/1981, de 13 de febrero, en relación con la libertad de cátedra, es la tantas veces citada sentencia 11/1981, de 8 de abril, la que trata de precisar su alcance. Dicho muy sucintamente: el TC considera igualmente válidas -e incluso complementarias - las dos vías que cabe seguir para determinar el contenido esen. cial de un derecho fundamental. De un lado, la vía que parte de la convicción de que el tipo abstracto de cada derecho fundamental «preexiste conceptualmente al momento legislativo» y que «en este sentido se puede hablar de una recognoscibilidad de ese tipo abstracto en la regulación concreta», de tal modo que «los especialistas en derecho pueden responder si lo que el legislador ha regulado se ajusta o no a lo que generalmente se entiende por un derecho de tal tipo». De otro lado, la vía que hace partir su investigación de los «intereses jurídicamente protegidos»: en este sentido, se rebasaría o se desconocería el «contenido esencial cuando el derecho queda sometido a limitaciones que lo hacen impracticable, lo dificultan más allá de lo razonable o lo despojan de la necesaria protección» ${ }^{114}$.

\subsubsection{Los limites de los derechos: los «servicios esenciales»}

EI TC ha recordado en diversas ocasiones cómo los derechos fundamentales no son «absolutos e ilimitados», que tienen «límites necesarios» ${ }^{115}$. Entre estos límites cabe destacar especialmente el relativo a los «servicios

${ }_{112}$ Fto. Jco. 5.

${ }^{113}$ Fto. Jco. 9. «Es derecho de los trabajadores colocar el contrato de trabajo en una fase de suspensión y de este modo limitar la libertad del empresario, a quien se le veda contratar otros trabajadores y llevar a cabo arbitrariamente el cierre de la empresa.»

${ }_{114}$ Fto. Jco. 8. Cfr. L. Parejo Alfonso, «El contenido esencial de los derechos fundamentales en la jurisprudencia constitucional; a propósito de la sentencia del Tribunal Constitucional de 8 de abril de 1981», en Revista Española de Derecbo Constitucional, 3 (1981), págs. 169-190. Jco. 7.

7 STC 36/1982, de 16 de junio, Fto. Jco. 6; STC 5/1981, de 13 de febrero, Fto. 
esenciales de las comunidad» que deben ser siempre mantenidos con ocasión del ejercicio del derecho de huelga ${ }^{116}$. El TC ha debido ocuparse del alcance de este concepto con ocasión de un recurso de inconstitucionalidad ${ }^{117}$ de un recurso de amparo ${ }^{118} \mathrm{y}$ del primero de los conflictos de competencia ${ }^{119}$.

Es en el mencionado recurso de amparo donde el TC perfila su concepción de los «servicios esenciales», a cuyos efectos, entre las que llama «concepciones amplia y estricta», opta por esta última, es decir, la que pone el acento no en los servicios o actividades mismas, sino en los bienes o intereses que han de ser satisfechos: "Como bienes e intereses esenciales hay que considerar los derechos fundamentales, las libertades públicas y los bienes constitucionalmente protegidos» ${ }^{20}$.

Por lo demás, la fijación de los servicios esenciales mínimos que deben ser prestados en cada caso debe ser realizada por una autoridad gubernativa, es decir, políticamente responsable, dada la naturaleza esencialmente política de la decisión ${ }^{121}$; la decisión, por último, debe ser en cada caso motivada, correspondiendo el onus probandi en caso de conflicto a la autoridad que ha fijado dichos servicios mínimos ${ }^{122}$.

\subsubsection{Efecto retroactivo de la Constitución en materia de derechos fundamentales}

Ya ha sido mencionado este principio con ocasión de la problemática del «derecho preconstitucional», principio establecido en la sentencia 9/1981, de 31 de marzo, confirmada días más tarde en la sentencia 10/1981, de 6. de abril ${ }^{123}$. En base al mismo, el TC ha otorgado amparo constitucional frente a una serie de actos de los poderes públicos que, aun producidos con anterioridad a la entrada en vigor de la Constitución, continúan haciendo sentir sus efectos. Algunas sentencias más recientes, sin embargo, parecen dar a entender que el TC ha abandonado o, al menos, prefiere no insistir en esta doctrina ${ }^{124}$.

\subsubsection{Efectos frente a terceros}

El art. 41.2 LOTC limita el alcance del «recurso de amparo» frente a violaciones procedentes de los poderes públicos, con lo que se plantea el problema de la protección de los derechos fundamentales en las relaciones entre particulares. Hasta el momento, el TC ha evitado tratar el problema de frente, aunque lo ha aludido de pasada en algún caso. Es expresivo a este respecto el intercambio de opiniones entre mayoría y minoría del TC en la senten-

116 Art. $28.2 \mathrm{CE}$.

117 STC 11/1981, de 8 de abril, Fto. Jco. 18.

118 STC 26/1981, de 17 de julio, Fto. Jco. 10.

119 STC 33/1981, de 5 de noviembre, Ftos. Jcos. 4 a 7.

120 STC 26/1981, de 17 de julio, Fto. Jco. 10.

121 STC 11/1981, de 8 de abril, Fto. Jco. 18; STC 26/1981, de 17 de julio, Fto. Jco. 11; STC 33/1981, de 5 de noviembre, Ftos. Jcos. 4 a 8.

${ }_{122}$ STC 26/1981, de 17 de julio, Ftos. Jcos. 14 y 16.

123 Véase supra, nota 21.

${ }_{124}$ STC 31/1982, de 3 de junio; Fto. Jco. 3. 
cia 5/1981, de 13 de febrero, en torno a la eventualidad de un recurso de amparo por parte de los profesores de un centro docente frente a la dirección del mismo ${ }^{125}$; en el caso de una empresa propiedad del Estado -frente a la cual se solicita el amparo-, el TC lo califica de «espinoso problema» ${ }^{126}$; cierto reconocimiento expreso del mismo parece deducirse respecto del derecho de reunión de los trabajadores dentro del centro de trabajo ${ }^{127}$; aun sin utilizar la expresión, el TC parece reconocerlo expresamente respecto del derecho de sindicación frente a las empresas ${ }^{128}$.

En la autorizada opinión de Rubio Llorente, la polémica en torno a la Drittwirkung debe encontrar solución en base al carácter subsidiario del recurso de amparo. En efecto, dado que el recurso de amparo va precedido - con sólo alguna excepción - de una resolución judicial, siempre será posible solicitar el amparo frente a dicha resolución cuando no hubiere puesto fin a una violación de derechos, cualquiera que hubiera sido el origen de la misma ${ }^{129}$.

\subsubsection{El principio de garantía material de los derechos fundamentales}

En la sentencia 42/1982, de 5 de julio, el TC sienta un principio de interpretación de los derechos fundamentales, potencialmente de gran trascendencia. A diferencia del Estado de Derecho, el Estado social de Derecho no puede conformarse con una garantía meramente «formal» de los derechos fundamentales, sino que exige una garantía «material» de los mismos; en otras palabras: no sólo su previsión legal, sino también su efectividad ${ }^{130}$.

\subsubsection{Los «principios rectores de la politica social y económica»}

Con este título, como es sabido, la CE recoge, en el capítulo III de su título I, una amplia tabla de derechos sociales (arts. 39 a 52). La garantía constitucional de estos derechos se halla contenida en el art. $53.3 \mathrm{CE}$ en términos imprecisos ${ }^{131}$. El TC apenas ha tenido ocasión de ocuparse de estos «principios»; cabe citar, sin embargo, el caso del principio de la política económica de pleno empleo (art. $40.1 \mathrm{CE}$ ) que el TC ha tenido ocasión de tomar en consideración a efectos de justificar el recurso a la jubilación forzosa anticipada como instrumento de dicha política económica ${ }^{132}$.

125 STC 5/1981, de 13 de febrero, Fto. Jco. 10, y voto particular primero, punto 3 .

${ }^{126}$ STC 26/1981, de 17 de julio, Fto. Jco. 7.

17 STC $18 / 1981$, de 8 de junio, Fto. Jco. 4.

${ }^{128}$ STC 38/1981, de 23 de noviembre, Fto. Jco. 5.

129 Cit. nota 40, pág. 66.

${ }^{130}$ Fto. Jco. 2.

131 Art. $53.3 \mathrm{CE}$ : «El reconocimiento, el respeto y la protección de los principios reconocidos en el capítulo III informarán la legislación positiva, la práctica judicial y la actuación de los poderes públicos. Sólo podrán ser alegados ante la jurisdicción ordinaria de acuerdo con lo que dispongan las leyes que los desarrollen.»

${ }_{132}$ STC 22/1981, de 2 de julio, Ftos. Jcos. 8 a 10. 


\subsubsection{La jurisprudencia del Tribunal Europeo de Derechos Humanos}

La Constitución española dispone que las normas relativas a los derechos fundamentales se interpreten de conformidad «con la Declaración Universal de Derechos Humanos y los tratados y acuerdos internacionales sobre las mismas materias ratificados por España» (art. 10.2 CE). En virtud de este precepto, el TC se ha servido de los derechos contenidos en las declaraciones internacionales como criterio de interpretación de los derechos fundamentales contenidos en la Constitución. Sin embargo, ha sido muy particularmente la jurisprudencia del Tribunal Europeo de Derechos Humanos la que ha sido invocada ante el TC, y que éste ha utilizado en ocasiones. Así cabe citar la jurisprudencia del TEDH sobre el principio de igualdad contenida en sus sentencias de 23 de julio de 1968 y de 27 de octubre de $1975^{133}$. Igualmente ha invocado el TC la sentencia de 17 de enero de 1970 (caso Delcourt) ${ }^{134}$, la relativa al caso König ${ }^{135}$ y al caso Engel ${ }^{136}$, entre otras.

\subsection{El Estado y las Comunidades Autónomas}

Sin duda, la patte más dificultosa —y al mismo tiempo más delicada políticamente- de la tarea del TC es la relativa a la interpretación de los preceptos constitucionales que configuran el nuevo modelo del Estado español, integrado por una pluralidad de nacionalidades y regiones dotadas de autonomía política - las Comunidades Autónomas - en el seno de la Nación española. El conjunto formado por el título VIII de la Constitución y los Estatutos de Autonomía, aprobados en base al mismo, integran un bloque normativo o sector del ordenamiento verdaderamente temible para el intérprete constitucional.

\subsubsection{La forma de Estado}

Ante todo, el TC se ha encontrado con dificultades terminológicas. En efecto, el Estado configurado en el título VIII de la Constitución no responde a ninguna de las formas de Estado tradicionalmente reconocidas: no es el Estado unitario, no es el Estado federal, no es tampoco el Estado «regional» de tipo italiano. El TC ha evitado cualquiera de estos términos para designar al Estado español, como ha evitado también el término más usual en la opinión pública española: «Estado de las Autonomías». En lugar de ello ha utilizado en alguna ocasión algún circunloquio ${ }^{137}$ o bien ha utilizado un tér-

${ }^{133}$ STC 22/1981, de 2 de julio, Fto. Jco. 3; STC 34/1981, de 10 de noviembre, Fto. Jco. 3.

${ }_{134}$ STC 12/1981, de 10 de abril, Fto. Jco. 3.

135 STC 24/1981, de 14 de julio, Fto. Jco. 3.

${ }^{136}$ STC $21 / 1981$, de 15 de junio, Ftos. Jcos. 9 y 10. En este supuesto concreto, el TC no consideró procedente la aplicación de la jurisprudencia contenida en la sentencia del TEDH en base a las reservas manifestadas por España con respecto a los artículos $5 .^{\circ}$ y $6 .^{\circ}$ del Convenio de Roma en base al art. 64 del mismo.

${ }_{137}$ «La forma de organización territorial del Estado configurada por la Constitución», «la nueva forma de organización territorial del Estado» (STC 26/1982, de 24 de mayo, Ftos. Jcos. 1 y 3 ). 
mino lo más formal posible: «institución compleja» ${ }^{138}$, «forma compuesta del Estado» ${ }^{139}$; quizá sea este último término el que se vea adoptado por el TC.

El TC, por el contrario, no ha tenido dificultades para advertir que el mismo término «Estado» es utilizado por la Constitución con dos significados diferentes: en unos casos, para designar al Estado «como totalidad de la organización jurídico-política de la Nación española»; en otros casos, para designar únicamente los órganos «centrales» o «generales» del Estado como contrapuestos a las instituciones u órganos de las Comunidades Autónomas ${ }^{140}$. La misma expresión «órganos generales» del Estado es de creación del TC, quien la utiliza alternativa o conjuntamente con la expresión órganos «centrales» ${ }^{141}$.

\subsubsection{El principio de autonomía y la doctrina de los intereses territoriales}

Con base en el artículo inicial del título VIII de la Constitución, que se refiere indistintamente a la «autonomía» de los municipios, de las provincias y de las Comunidades Autónomas ${ }^{142}$, el TC comenzó elaborando un concepto de «autonomía» más o menos indiferenciado, aplicable por igual a cada uno de estos entes territoriales. Según esta concepción, la «autonomía», como principio constitucional de organización territorial del Estado, encuentra su justificación en la existencia de unos intereses territoriales particulares o específicos, limitados a un determinado ámbito territorial. Estos intereses territoriales fundamentarían la atribución de una serie de competencias, el conjunto de las cuales constituiría la autonomía de cada ente territorial, ya sea éste el municipio, la provincia o la Comunidad Autónoma. Ciertamente se reconocía que había diferencias entre las autonomías de cada uno de estos entes territoriales, pero la concepción básica era la misma: la «autonomía» de los distintos entes territoriales, como ámbito de los intereses particulares y de las competencias limitadas, se contraponía a la «soberanía» del Estado, como ámbito de los intereses generales y de las competencias potencialmente ilimitadas.

Esta concepción de la «autonomía», elaborada con ocasión de un recurso que hacía referencia precisamente a la legislación de «régimen local» (municipios y diputaciones provinciales), es aplicada exhaustivamente en la sentencia relativa al recurso contra la «Ley Antiterrorista», concluyendo el TC

${ }^{138}$ STC 38/1982, de 22 de junio, Fto. Jco. 2.

139 STC 35/1982, de 14 de junio, Fto. Jco. 2.

${ }_{140}$ STC 32/1981, de 28 de julio, Fto. Jco. 5.

${ }^{14}$ Así, el TC habla de «órganos generales del Estado» en la primera sentencia sobre un recurso de inconstitucionalidad (STC 4/1981, de 2 de febrero, Fto. Jco. 2); el segundo voto particular de la STC 5/1981, de 13 de febrero, habla de «poderes generales»; la STC 37/1981, de 16 de noviembre, habla de «instituciones generales» e incluso de «ley general o ley emanada de los órganos generales del Estado» (Fto. Jco. 2).

${ }^{242}$ Art. 137: «El Estado se organiza territorialmente en municipios, en provincias y en las Comunidades Autónomas que se constituyan. Todas estas entidades gozan de autonomía para la gestión de sus respectivos intereses.» 
- como ha habido ocasión de ver- la ausencia de legitimación de la Comunidad Autónoma para impugnar dicha ley ${ }^{143}$.

Puede decirse, sin embargo, que a partir de ese momento el TC ha ido distanciándose de estos planteamientos iniciales que mantenían la autonomía de las Comunidades Autónomas en un ámbito no muy lejano al de la autonomía administrativa para acentuar la especificidad del concepto de autonomía aplicado a las Comunidades Autónomas. El punto de inflexión puede ser considerada la sentencia relativa a las Diputaciones catalanas, en la que ya se observa un distanciamiento respecto de la teoría de los «intereses naturales», utilizando la expresión «autonomía política» para referirla a las Comunidades Autónomas. La línea argumental, sin embargo, sigue siendo similar a la de la jurisprudencia anterior. En particular se mantiene el equívoco relativo a la «soberanía del Estado» susceptible de ser entendido como soberanía de los órganos centrales del Estado, lo que carece de base en la Constitución ${ }^{144}$. Será, sin embargo, la sentencia 37/1981, de 16 de noviembre, la que descalifique la doctrina de los «intereses territoriales» como instrumento operativo en la labor del juez constitucional, llevando a cabo una interpretación bastante más comprensiva respecto de las consecuencias que sobre el Estado ha de tener la implantación de las Comunidades Autónomas ${ }^{145}$.

En esta misma línea hay que destacar la sentencia dictada con ocasión del primer conflicto de competencias, en la que se confirma decididamente el carácter «político» de los órganos de las Comunidades Autónomas y su competencia para asumir funciones de trascendencia "política» ${ }^{146}$.

\subsubsection{La distribución de competencias: \\ La noción «material» de «bases»}

La interpretación de las normas constitucionales y estatutarias que regulan la distribución de competencias entre el Estado y las Comunidades Autónomas está constituyendo la tarea probablemente más importante del TC en este momento. A modo de ejemplo, de esta labor interpretativa cabe destacar el principio de la «noción material de bases».

El origen de este problema se halla en la forma de distribución de competencias establecida en la Constitución, muy particularmente en su artículo 149.1, el cual reserva al Estado «las bases» de determinadas materias ${ }^{147}$; el resto de las competencias sobre dichas materias, es decir, las «no básicas»,

${ }^{143}$ STC 4/1981, de 2 de febrero, Fto. Jco. 3, y STC 25/1981, de 14 de julio, Fto. Jco. 3 .

i4 STC 32/1981, de 28 de julio, Ftos. Jcos. 3 y 4.

${ }^{145}$ Fto. Jco. 1.

${ }_{140}$ STC $33 / 1981$, de 5 de noviembre, Fto. Jco. 6. La competencia, en este caso, era la relativa a la fijación de los «servicios esenciales» con ocasión de una huelga en el Metro de Barcelona. Una jurisprudencia anterior del TC había exigido que esta decisión fuese adoptada por autoridades gubernativas, dotadas de responsabilidad política; frente a la opinión del representante del Gobierno (del Estado), el TC declara que las autoridades de la Comunidad Autónoma son autoridades de esa naturaleza.

${ }_{147}$ Así, art. 149.1.11.: «bases de la ordenación de crédito, banca y seguros»; artículo 149.1.18. : «bases del régimen jurídico de las Administraciones públicas y del régimen estatutario de sus funcionarios», entre otros. 
pueden ser asumidas por las Comunidades Autónomas a través de sus respectivos «Estatutos de Autonomía» (art. 149.3). Ahora bien, a diferencia de lo que ocurre en los Estados federales, en un Estado en el que, como es el caso del español, se lleva a efecto un proceso de descentralización política, ocurre que inicialmente todo el derecho es derecho estatal: el derecho «autonómico» tiene que ir surgiendo necesariamente en forma de «desplazamiento» local del derecho estatal vigente ${ }^{148}$. Concretamente, cuando se trata de una materia respecto de la cual el Estado detenta la competencia sobre «las bases» de la misma, correspondiendo el resto a la Comunidad Autónoma, se plantea el problema de cuáles sean esas «bases». ¿Sería necesario esperar a que el Estado dictase una «ley de bases» relativa a la materia en cuestión, a fin de que la Comunidad Autónoma pudiese comenzar a ejercer las competencias que le correspondiesen a partir de dicha «ley de bases»? Aquí es donde se inserta la doctrina del TC relativa a la «noción material de bases»: en virtud de la misma, las Comunidades Autónomas no habrán de esperar a que «el Estado» dicte tal legislación de base (lo que supondría una concepción «formal» de la misma) porque tales bases existen ya materialmente en el ordenamiento, siendo posible deducirlas racionalmente a partir de dicho ordenamiento ${ }^{149}$. Corresponderá a los poderes públicos, tanto «centrales» como «autonómicos», mediante una operación de deducción lógica, decidir qué es lo que debe considerarse «básico» en la regulación de una determinada materia, correspondiendo la decisión última en caso de conflicto al TC.

Esta «noción material de bases» no sólo supone el distanciamiento de la ley -formal- de bases, sino también de la misma noción de ley formal. En efecto, lo materialmente básico respecto de una determinada materia no tendría que expresarse necesariamente a través de una ley formal; en determinados casos, y con respecto a determinadas materias, algunas competencias de ejecución son de tal trascendencia que deben corresponder al ejecutivo estatal, al Gobierno estatal en cuanto «materialmente básicas». Tales serían las medidas coyunturales de regulación del crédito, que habrían de ser adoptadas por el Gobierno del Estado ${ }^{150}$.

Pero, en definitiva, toda esta jurisprudencia constitucional en materia de competencias se halla pendiente de la mencionada «Ley Orgánica de Armonización del Proceso Autonómicos (LOAPA) y, antes que ella y sobre todo, de la futura STC en el recurso previo interpuesto contra el proyecto de dicha ley ${ }^{151}$. Y se da la paradoja de que una norma que aspira a ser la compañera por excelencia —en cuanto interpretadora- de la Constitución en lo que, con cierta impropiedad, se empieza a llamar también aquí el «bloque de la constitucionalidad», es decir, a formar parte del parámetro o sujeto del control de constitucionalidad, ad usum sobre todo del TC, deba nacer —en vir-

14 Cfr. I. de Otto, «La prevalencia del derecho estatal sobre el derecho regional», en Revista Española de Derecho Constitucional, 2 (1981) págs. 57-92.

14 STC 32/1981, de 28 de julio, Fto. Jco. 6: «La noción de bases o de normas básicas ha de ser entendida como noción material, y, en consecuencia, esos principios o criterios básicos, estén o no formulados como tales, son los que racionalmente se deducen de la legislación vigente».

${ }_{150}$ STC $1 / 1982$, de 28 de enero, Fto. Jco. 1.

15t Véase supra, nota 96. 
tud del control «previo»- ya interpretada por el propio TC ${ }^{152}$. En todo caso hay acuerdo en reconocer que el TC se encuentra en esta ocasión ante el más importante juicio de constitucionalidad que le ha sido planteado hasta el presente.

\section{CONCLUSION}

Por una coincidencia, quizá no exenta de significado, las primeras sentencias del TC salían publicadas en la mañana del 24 de febrero de 1981, con el Congreso de los Diputados y el Gobierno en funciones secuestrados en el Palacio de las Cortes. Desde entonces, el TC, y a través de 101 sentencias, ha acumulado una importante doctrina constitucional, desde luego sin precedentes en nuestra historia constitucional, convirtiéndose efectivamente en el órgano concebido por la Constitución: el garante del ordenamiento constitucional de 1978.

Quizá sea esto lo primero que llame la atención de la labor del TC en sus dos primeros años de funcionamiento: la madurez con que se ha enfrentado, desde sus primeras sentencias, con su función de «intérprete supremo de la Constitución». Para ello se ha beneficiado, indudablemente, de la misma madurez alcanzada por el Derecho constitucional desde la segunda posguerra, así como de la experiencia acumulada por los Tribunales Constitucionales europeos $\mathrm{y}$, más generalmente, por las diferentes formas de justicia constitucional. En este sentido, la jurisprudencia del TC español puede ser considerada como una prueba más de la autonomía alcanzada por el Derecho constitucional como ciencia de la norma suprema del Estado jurídicamente garantizada.

Lo segundo que viene a confirmar, en nuestra opinión, la experiencia jurisprudencial española es la solidez y, en buena medida, el carácter insustituible - en los países de la tradición jurídica y política continental- del sistema de justicia constitucional «concentrada» (o, más correctamente, parcialmente «concentrada»). Sólo un órgano constitucional concebido con esta misión específica hubiera podido llevar a cabo en nuestro país la labor realizada en tan poco tiempo por el TC en pro de la efectividad de la supremacía de la Constitución. Con un sistema de justicia constitucional «difuso», basado exclusivamente en el Poder Judicial, esto no hubiera sido sencillamente posible: baste recordar la lamentada «infrautilización» del control concreto de constitucionalidad.

Es quizá todavía pronto -y tampoco ha sido éste el objeto de este informe- para analizar $\mathrm{y}$, menos aún, valorar los hábitos y técnicas interpretativas del TC. Sí está desde luego probada su convicción de que interpretar con la máxima autoridad la Constitución sólo en último término supone de-

15. «Bloque de constitucionalidad» (STC 26/1982, de 24 de mayo, Fto. Jco. 2); «bloque constitucional» (STC 39/1982, de 30 de junio, Fto. Jco. 2); «bloque constitucional» (STC 39/1982, de 30 de junio, Fto. Jco. 3); un circunloquio quizá más prudente (STC 29/1982, de 31 de mayo, Fto. Jco. 3): «bloque normativo a que se refiere el art. 28 de la LOTC». ¿Son igualmente legítimas, por lo demás, las «sentencias interpretativas» en los supuestos de control previo? 
clarar la nulidad de un precepto legal. Antes de ello se hallan todas las posibilidades de la «interpretación conforme» e incluso de las «sentencias interpretativas». Ciertamente no se halla madura en nuestro país la polémica acerca de qué sea más respetuoso con el legislador, y en último término con la Constitución, si la sentencia anulatoria o la sentencia interpretativa, o si acaso no sería preferible introducir por vía legislativa la fórmula austríaca de la declaración de nulidad con eficacia retardada antes que permitir una proliferación, del modo que sea, de las sentencias interpretativas. Conforme su prestigio aumenta - y su prestigio no ha hecho más que aumentar desde la fecha de su constitución-, corre éste el peligro de que se pierda conciencia - no sólo por parte de él mismo, sino, sobre todo, por parte de otros protagonistas del proceso constitucional (LOAPA) - de sus propios límites y limitaciones. También frente a su propio prestigio habrá de protegerse el Tribunal Constitucional español.

(Concluido en septiembre de 1982.) 